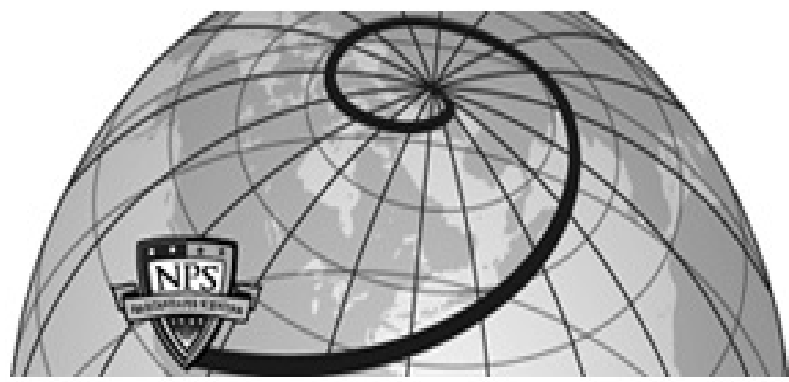

Calhoun: The NPS Institutional Archive DSpace Repository

2012-09

\title{
Analysis of Lean Initiatives in the Production of Naval Aviators
}

Prebula, Albert J., III

Monterey, California. Naval Postgraduate School

http://hdl.handle.net/10945/17442

Downloaded from NPS Archive: Calhoun

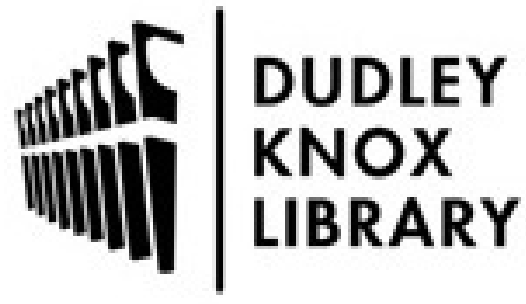

http://www.nps.edu/library
Calhoun is the Naval Postgraduate School's public access digital repository for research materials and institutional publications created by the NPS community. Calhoun is named for Professor of Mathematics Guy K. Calhoun, NPS's first appointed -- and published -- scholarly author.

Dudley Knox Library / Naval Postgraduate School 411 Dyer Road / 1 University Circle Monterey, California USA 93943 


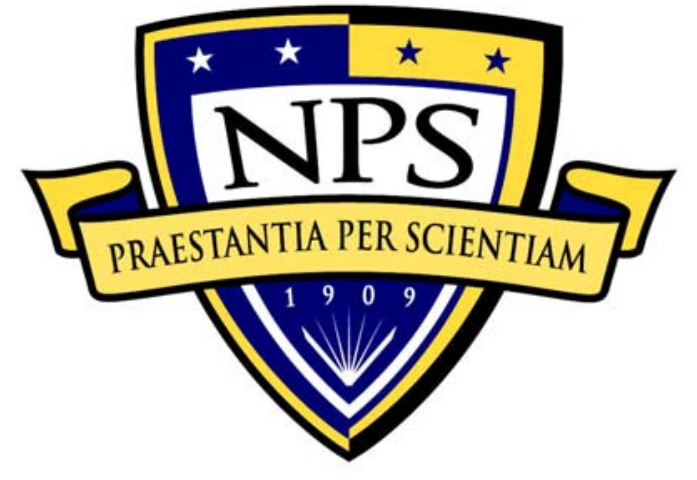

\section{NAVAL \\ POSTGRADUATE \\ SCHOOL}

MONTEREY, CALIFORNIA

\section{JOINT APPLIED PROJECT}

Analysis of Lean Initiatives in the Production of Naval Aviators

By: Albert J. Prebula III

September 2012

Advisors: Keebom Kang

David Lobdell 
THIS PAGE INTENTIONALLY LEFT BLANK 

searching existing data sources, gathering and maintaining the data needed, and completing and reviewing the collection of information. Send comments regarding this burden estimate or any other aspect of this collection of information, including suggestions for reducing this burden, to Washington headquarters Services, Directorate for Information Operations and Reports, 1215 Jefferson Davis Highway, Suite 1204, Arlington, VA 22202-4302, and to the Office of Management and Budget, Paperwork Reduction Project (0704-0188) Washington DC 20503.

\begin{tabular}{|l|l|}
\hline 1. AGENCY USE ONLY (Leave blank) & $\begin{array}{l}\text { 2. REPORT DATE } \\
\text { September } 2012\end{array}$ \\
\hline
\end{tabular}

4. TITLE AND SUBTITLE Analysis of Lean Initiatives in the Production of Naval Aviators

6. AUTHOR(S) Albert J. Prebula III

7. PERFORMING ORGANIZATION NAME(S) AND ADDRESS(ES)

Naval Postgraduate School

Monterey, CA 93943-5000

9. SPONSORING /MONITORING AGENCY NAME(S) AND ADDRESS(ES) N/A
3. REPORT TYPE AND DATES COVERED Joint Applied Project
8. PERFORMING ORGANIZATION REPORT NUMBER

10. SPONSORING/MONITORING AGENCY REPORT NUMBER

11. SUPPLEMENTARY NOTES The views expressed in this thesis are those of the author and do not reflect the official policy or position of the Department of Defense or the U.S. Government. I.R.B. Protocol number N/A.

12a. DISTRIBUTION / AVAILABILITY STATEMENT

Approved for public release; distribution unlimited

12b. DISTRIBUTION CODE

\section{ABSTRACT (maximum 200 words)}

The Department of the Navy is dealing with shrinking budgets and increased training requirements for the production of Naval Aviators for $4^{\text {th }}$ and $5^{\text {th }}$ generation Navy aircraft. Lean and Six Sigma strategies are routinely used in today's manufacturing processes. The U.S. military is saving billions of dollars by implementing quality improvement methods such as Lean Six Sigma, and these savings could grow even faster as the Department of Defense takes steps to expand these initiatives throughout the armed services.

The purpose of this Joint Applied Project is to investigate and study the application of lean thinking in the production of Navy pilots. The Chief of Naval Air Training's (CNATRA) strategic vision supposes that lean initiatives can be implemented in the training process and has made moves to streamline and create better value in the production of Navy aircrew. This paper will analyze the Naval Aviation Enterprise and CNATRA's lean training initiatives and compare them to typical lean manufacturing initiatives. This paper will also examine current policies and procedures to determine if current lean initiatives are meeting their intended objectives and goals. Further analysis will determine if improvements can be made to lean policies in order to increase efficiency and effectiveness over the entire "value stream” or "aircrew training continuum."

14. SUBJECT TERMS Lean, CNATRA, Naval Aviation Enterprise, NAPP, Naval Aviation Training, Naval Aviators, Navy Aircrew

\section{NUMBER OF} PAGES

69

\section{PRICE CODE}

\section{SECURITY CLASSIFICATION OF REPORT}

NSN 7540-01-280-5500

18. SECURITY
CLASSIFICATION OF THIS
PAGE

Unclassified

19. SECURITY
CLASSIFICATION OF
ABSTRACT
$\quad$ Unclassified
CLASSIFICATION OF Unclassified ABSTRACT

$\mathrm{UU}$

Standard Form 298 (Rev. 2-89) Prescribed by ANSI Std. 239-18 
THIS PAGE INTENTIONALLY LEFT BLANK 
Approved for public release; distribution is unlimited

\title{
ANALYSIS OF LEAN INITIATIVES IN THE PRODUCTION OF NAVAL AVIATORS
}

\author{
Albert J. Prebula III, Lieutenant Commander, United States Navy \\ Submitted in partial fulfillment of the requirements for the degree of \\ MASTER OF SCIENCE IN PROGRAM MANAGEMENT \\ from the \\ NAVAL POSTGRADUATE SCHOOL \\ September 2012
}

Authors:

Albert J. Prebula III

Approved by:

Dr. Keebom Kang, Lead Advisor

CAPT David Lobdell, USN, Support Advisor

William R. Gates, Dean

Graduate School of Business and Public Policy 
THIS PAGE INTENTIONALLY LEFT BLANK 


\title{
ANALYSIS OF LEAN INITIATIVES IN THE PRODUCTION OF NAVAL AVIATORS
}

\begin{abstract}
The Department of the Navy is dealing with shrinking budgets and increased training requirements for the production of Naval Aviators for $4^{\text {th }}$ and $5^{\text {th }}$ generation Navy aircraft. Lean and Six Sigma strategies are routinely used in today's manufacturing processes. The U.S. military is saving billions of dollars by implementing quality improvement methods such as Lean Six Sigma, and these savings could grow even faster as the Department of Defense takes steps to expand these initiatives throughout the armed services.

The purpose of this Joint Applied Project is to investigate and study the application of lean thinking in the production of Navy pilots. The Chief of Naval Air Training's (CNATRA) strategic vision supposes that lean initiatives can be implemented in the training process and has made moves to streamline and create better value in the production of Navy aircrew. This paper will analyze the Naval Aviation Enterprise and CNATRA's lean training initiatives and compare them to typical lean manufacturing initiatives. This paper will also examine current policies and procedures to determine if current lean initiatives are meeting their intended objectives and goals. Further analysis will determine if improvements can be made to lean policies in order to increase efficiency and effectiveness over the entire "value stream" or "aircrew training continuum.”
\end{abstract}


THIS PAGE INTENTIONALLY LEFT BLANK 


\section{TABLE OF CONTENTS}

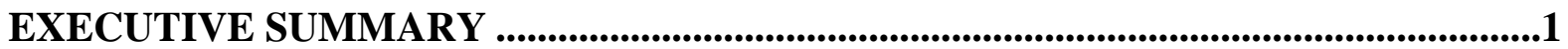

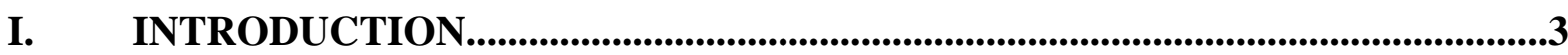

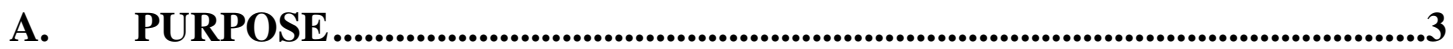

B. SCOPE AND LIMITATIONS ........................................................................4

C. RESEARCH PROJECT OBJECTIVE ...............................................................4

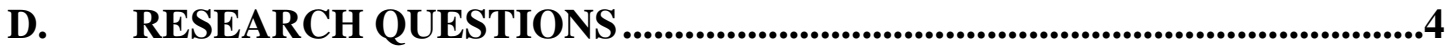

E. METHODOLOGY .........................................................................................5

1. Data Collection Methodology ..........................................................5

2. Data Analysis Methodology ..................................................................5

3. Conclusions and Recommendations Methodology ............................5

F. RESEARCH PROJECT REPORT ORGANIZATION ............................5

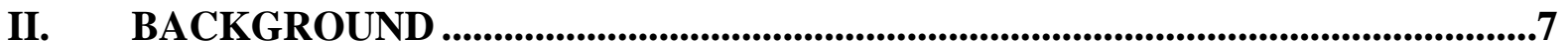

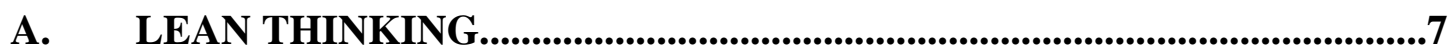

1. Specify Value ..................................................................................................7

2. Identify Value Stream...........................................................................8

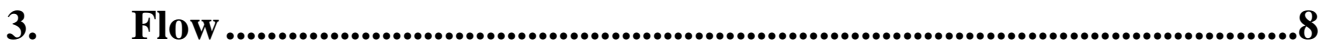

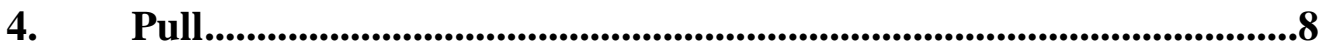

5. Perfection............................................................................................99

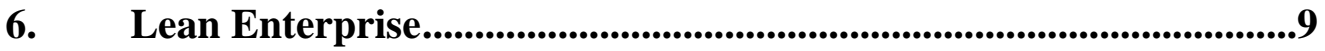

7. Enterprise Transformation.....................................................................9

B. THE NAVAL AVIATION ENTERPRISE ..............................................10

1. Enterprise Framework ..................................................................10

2. Enterprise Guiding Principles ......................................................11

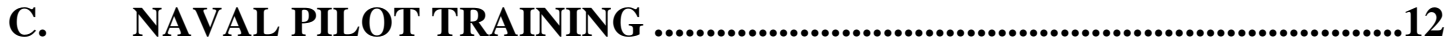

1. Pilot Training Pipeline.....................................................................12

D. BEGINNINGS OF LEAN IN NAVAL AVIATION TRAINING..............14

1. Naval Aviation Production Process Improvement Program .........14

2. Naval Aviation Enterprise AirSpeed Program ................................15

3. Naval Aviation Enterprise Lean Training Transformation ...........18

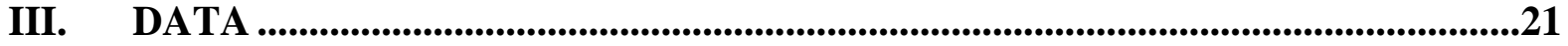

A. SPECIFY VALUE IN TRAINING.........................................................21

B. TRAINING VALUE STREAM .................................................................24

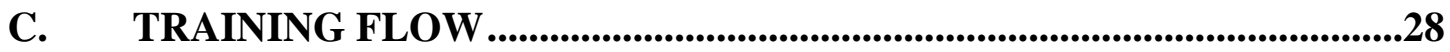

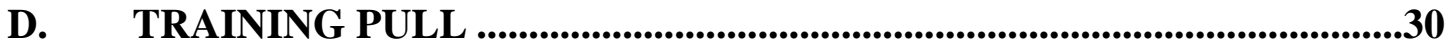

E. TRAINING PERFECTION ............................................................................32

F. NAVAL AVIATION LEAN TOOLS ..................................................33

1. NAPP Metrics......................................................................................33

2. Training Integrated Management System (TIMS)........................36

3. Multi-Service Pilot and NFO Training System (MPTS/MNTS)....37

4. Future Tools .............................................................................38 


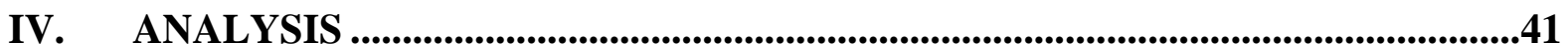

A. SPECIFY VALUE IN TRAINING................................................................41

B. TRAINING VALUE STREAM ............................................................41

C. TRAINING FLOW ............................................................................................42

D. TRAINING PULL .........................................................................................44

E. TRAINING PERFECTION ..............................................................................44

V. CONCLUSIONS AND RECOMMENDATIONS.....................................................47

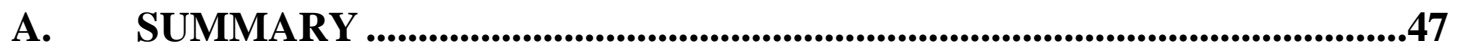

B. RECOMMENDATIONS.....................................................................................47

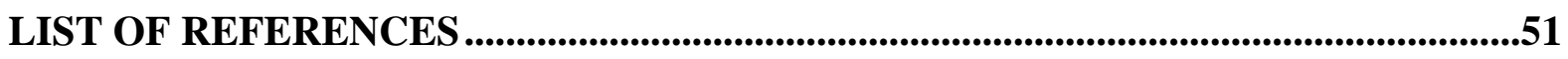

INITIAL DISTRIBUTION LIST ............................................................................................53 


\section{LIST OF FIGURES}

Figure 1. The Naval Aviation Enterprise (From: NAE, 2012)........................................10

Figure 2. CNATRA Pilot Training Pipeline / Value Stream Map (From: CNATRA,

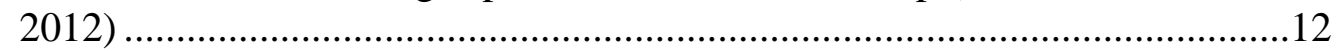

Figure 3. $\quad$ Fleet Replacement Squadron Locations (From: CNATRA, 2012)..................13

Figure 4. $\quad$ History of AIRSpeed (From: Moore, 2007) …………………………...........18

Figure 5. $\quad$ Naval Aviation Enterprise (From: Moore, 2007) ………………………......19

Figure 6. Internal Primary Value Stream (From: Crabbe, 2011) ....................................25

Figure 7. $\quad$ Primary Flight Training Programed Flights/Hours (From: Crabbe, 2011)....26

Figure 8. $\quad$ Spring 12 Strike/ Fighter Integrated Production Plan.....................................2.

Figure 9. The NAPP Management Process, (From: Sizemore, 2010) …………............28

Figure 10. VT-7 USMC Events Per Day Required ....................................................29

Figure 11. NAPP Pull Requirements Flow Chart (From: Sizemore, 2010).......................31

Figure 12. VT-7 Events Per Day Required .......................................................................34

Figure 13. VT-7 Squadron Planned vs. Actual ……….....................................................

Figure 14. Instructor Pilot Manning .............................................................................36 
THIS PAGE INTENTIONALLY LEFT BLANK 


\section{LIST OF TABLES}

Table 1. Primary Course Training Standard (From: Crabbe, 2009) ............................38 
THIS PAGE INTENTIONALLY LEFT BLANK 


\section{ACKNOWLEDGMENTS}

The author wants to thank his family, especially his wife, Dawn, for her enduring support throughout this project. She was essentially a single parent of three children, one

of whom was 5 months old, during a cross-country PCS, as this project came to completion. 
THIS PAGE INTENTIONALLY LEFT BLANK

xiv 


\section{EXECUTIVE SUMMARY}

This research project examines the lean initiatives that are being implemented in the production of Navy aircrew. "On March 9, 2006, the Chief of Naval Operations (CNO) approved the alignment of CNATRA under Commander, Naval Air Forces (CNAF), to be effective in Fiscal Year (FY) 2007. The goal of this alignment is to fully leverage the core competencies of both Manpower, Personnel, Training \& Education (MPT\&E) and the Naval Aviation Enterprise (NAE) in the production of aircrew. The arrangement improves the NAE span of control over naval aviator and aircrew production and aircraft, allowing better management of aviator production capacity within the Fleet force structure, while aligning CNATRA's approximately 725 aircraft within the Naval Air Force. By setting up student "Street to Seat" under MPT\&E and "Seat to Fleet" under the NAE, efficiencies will be gained in standardization of Production Planning Factors, alignment of Fleet Replacement Squadron (FRS) and Training Command (TRACOM) curricula, and the potential download of training hours from more expensive cost-perhour FRS aircraft to less expensive TRACOM aircraft. Under this construct, CNATRA's budget will shift from training resources to readiness resources, allowing rapid shift of training down to the lowest cost asset, providing the greatest training benefit at the lowest possible cost. (Quinn, 2007)

Lean and Six Sigma strategies are routinely used in today's manufacturing processes. CNATRA's strategic vision believes that lean initiatives can be implemented and has made moves to streamline and create better value in the training of Navy aircrew. This paper will analyze CNATRA lean training initiatives and compare them to typical lean manufacturing initiatives. This research project focuses on how the Naval Aviation Enterpise's lean initiatives have improved pilot production, by using better stakeholder cooperation, standard time-train, and task breakdown metrics. Finally, recommendations for improvement and continued research will be suggested in order to further refine the production training of a Navy pilot at the "best-value." 
THIS PAGE INTENTIONALLY LEFT BLANK 


\section{INTRODUCTION}

\section{A. PURPOSE}

This research project examines the lean initiatives that are being implemented in the production of Navy aircrew.

On March 9, 2006, the Chief of Naval Operations (CNO) approved the alignment of CNATRA under Commander, Naval Air Forces (CNAF), to be effective in Fiscal Year (FY) 2007. The goal of this alignment is to fully leverage the core competencies of both Manpower, Personnel, Training \& Education (MPT\&E) and the Naval Aviation Enterprise (NAE) in the production of aircrew. The arrangement improves the NAE span of control over naval aviator and aircrew production and aircraft, allowing better management of aviator production capacity within the Fleet force structure, while aligning CNATRA's approximately 725 aircraft within the Naval Air Force. By setting up student "Street to Seat" under MPT\&E and "Seat to Fleet" under the NAE, efficiencies will be gained in standardization of Production Planning Factors, alignment of Fleet Replacement Squadron (FRS) and Training Command (TRACOM) curricula, and the potential download of training hours from more expensive cost-per-hour FRS aircraft to less expensive TRACOM aircraft. Under this construct, CNATRA's budget will shift from training resources to readiness resources, allowing rapid shift of training down to the lowest cost asset, providing the greatest training benefit at the lowest possible cost. (Quinn, 2007, p. 4)

Lean and Six Sigma strategies are routinely used in today's manufacturing processes. What if that manufacturing process is the production of a Naval Aviators? Can the same principles be applied when working with training systems and the product is a person? CNATRA's strategic vision believes that lean initiatives can be implemented and has made moves to streamline and create better value in the training of Navy aircrew. This paper will analyze CNATRA lean training initiatives and compare them to typical lean manufacturing initiatives. This research project focuses on how the NAE lean initiatives have improved pilot production by using better stakeholder cooperation, standard time-to-train, and task breakdown metrics. Finally, recommendations for improvement and continued research will be provided in order to further refine the production training of a Navy pilot at the "best-value." 
The results of this project will provide leaders with insight of how lean initiatives can be implemented and managed in the complex task of training aircrew. This knowledge will help facilitate further successful implementation of lean initiatives in other training environments. These lean training concepts could also be used in other government organizations resulting in increased efficiency, cost savings and higher quality training. Lean training concepts could be applied very effectively in other complex training environments like Special Operations.

\section{B. SCOPE AND LIMITATIONS}

The scope of this project focuses on lean implementation and how it may be applied to the training process of Navy Pilots. The Naval Aviation Enterprise is implementing lean concepts throughout all training systems, but the Strike/Fighter aircrew pipeline is the most resource intensive and has the longest value stream. Detailed examination of all Naval Aviation training pipelines was beyond the scope of this report. This report will focus mainly on the Strike/Fighter pipeline and associated value streams.

\section{RESEARCH PROJECT OBJECTIVE}

This research project examines and assesses the implementation of lean initiatives in the Navy's Strike/Fighter Training continuum and identifies recommendations for improvements. Can lean thinking be applied to the training of aircrew from "street-tofleet”? Processes used during the lean implementation are evaluated to identify issues, obstacles and lessons learned. This report will serve as a documented case study of the past and current lean initiatives when applied to a training environment.

\section{RESEARCH QUESTIONS}

What is lean thinking and how does it apply to Naval Aviation training?

How do you define value in Naval Aviation training?

How do you identify and integrate management of the entire training value stream?

How do you design production training systems that ensure training flows? 
How do you introduce a pull training production system to support customer needs?

How do you continuously improve all business activities to achieve perfection in training?

What tools are being used to implement lean training in Naval Aviation training?

\section{E. METHODOLOGY}

\section{Data Collection Methodology}

Data was collected from the Training Wing One NAPP program analysts. Policies, Strategic Visions, SOPs and procedures were collected from Naval Aviation Enterprise websites.

\section{Data Analysis Methodology}

Data were presented and correlated to how well the Naval Aviation Enterprise is using lean concepts in the training of Naval Aviators.

\section{Conclusions and Recommendations Methodology}

Conclusions and recommendations were based on data analysis and Naval Aviation Enterprise policies. These results should enable other government organizations to understand how lean thinking can be applied to training, as it is applied to any manufacturing processes.

\section{F. RESEARCH PROJECT REPORT ORGANIZATION}

Chapter I: Introduction-This chapter is an introduction to the purpose of this project as well as the significance of the research. The scope provides parameters of the research and conveys any limitations in the research. Concluding the chapter are the research questions this study investigates. 
Chapter II: Background-This chapter provides a review of Lean Thinking concepts. A current breakdown of the Naval Aviation Enterprise and Flight training pipeline are outlined. In this chapter, a brief history of recent Naval Aviation Lean programs are introduced.

Chapter III: Data-This chapter provides more Lean thinking concepts and how they correlate to Naval Aviation Enterprise Process improvement initiatives. In addition, data products are provided to highlight lean concepts in use.

Chapter IV: Analysis-This chapter is an analysis on how well the Naval Aviation Enterprise process improvements are progressing.

Chapter V: Conclusions and Recommendations-This chapter presents conclusions and recommendation for further implementation of lean initiatives in government training activities. 


\section{BACKGROUND}

\section{A. LEAN THINKING}

"Penchant for process improvement is inherent in human nature; even our distant ancestors discovered a better way to start fire, make arrowheads and spears, or build shelters" (Dershin, 2004). "Origins of Lean Production can be traced to the Scientific Management principles of Frederic Taylor (1911) and to the practical genius of Henry Ford" (Levinson, 2002). The concept of "Lean" originated in the 1950s with an engineer named Eji Toyoda, and a production genius Taiichi Ohno at Toyota in Japan. Toyoda and Ohno are credited with moving away from mass production by pioneering what is known today as TPS or Lean production. Shigeo Shingo originally published a study of the TPS in Japanese and later an English translation in 1981. Three American researchers, James Womack, Daniel Jones, and Daniel Roos, documented the origins and elements of Lean production during a five-year project sponsored by the Massachusetts Institute of Technology's (MIT’s) International Motor Vehicle Program. In their popular 1990 book titled The Machine That Changed the World, they highlighted that TPS uses 1/2 the human effort in the factory, $1 / 2$ the manufacturing space, $1 / 2$ the investment tools, $1 / 2$ the engineering hours and $1 / 2$ the time to develop new products (Womack, Jones \& Roos, 1990). In short, lean thinking is lean because it provides a way to do more and more with less and less-human effort, less equipment, less time, and less space-while coming closer and closer to providing customers with exactly what they want (Womack \& Jones, Lean Thinking, 1996).

\section{Specify Value}

"The critical starting point for lean thinking is value. Value can only be defined by the ultimate customer. And it's only meaningful when expressed in terms of a specific product (a good or a service, and often both at once) which meets the customer's needs at a specific price at a specific time” (Womack \& Jones, 1996, p. 16). 


\section{Identify Value Stream}

The Value stream is the set of all the specific actions required to bring a specific product (whether a good, a service, or, increasingly, a combination of the two) through the three critical management tasks of any business: the problem-solving task running from concept through detailed design and engineering to production launch, the information management task running from order-taking through detailed scheduling to delivery, and the physical transformation task proceeding from raw materials to a finished product in the hands of customer. Identifying the entire value stream for each product (or in some cases for each product family) is the next step in lean thinking, a step which firms have rarely attempted but which almost always exposes enormous, indeed staggering, amounts of muda or waste (Womack \& Jones, 1996).

\section{Flow}

"Once value has been precisely specified, the value stream for a specific product fully mapped by the lean enterprise, and obviously wasteful steps eliminated, it's time for the next step in lean thinking - a truly breathtaking one: Make the remaining, valuecreating steps flow” (Womack \& Jones, 1996, p. 21).

\section{Pull}

Pull in simplest terms means that no one upstream should produce a good or service until the customer downstream ask for it. The first visible effect of converting from departments and batches to product teams and flow is that the time required to go from concept to launch, sale to delivery, and raw material to the customer falls dramatically. When flow is introduced, products requiring years to designs are done in months, orders taking days to process are completed in hours, and weeks or months of throughput time for conventional physical production are reduced to minutes or days (Womack \& Jones, 1996). 


\section{Perfection}

As organizations begin to accurately specify value, identify the final value stream, make the value-creating steps for specific products flow continuously, and let customers pull value from the enterprise, something very odd begins to happen. It dawns on those involved that there is no end to the process of reducing effort, time, space, cost, and mistakes while offering a product which is ever more nearly what the customer actually wants. Suddenly perfection, the fifth and final principle of lean thinking, does not seem like a crazy idea (Womack \& Jones, 1996).

\section{Lean Enterprise}

The objective of the lean enterprise is very simple: Correctly specify value for the customer, avoiding the normal tendency for each firm along the stream to define value differently to favor its own role in providing it (for example: the manufacture who thinks the physical product itself is the customer's primary interest, the independent sales and service company that believes responsive customer relations account for most of the value perceived by the customer, etc.). Then identify all the actions required to bring a product from concept to launch, from order to delivery, and from raw material into the hands of the customer and on through its useful life. The mechanism of the lean enterprise is also very simple: a conference of all the firms along the stream, assisted by technical staff from "lean functions" in the participating firms, to periodically conduct rapid analyses and then to take fast-strike improvement actions (Womack \& Jones, 1996).

\section{Enterprise Transformation}

Enterprise transformation is the taking of an enterprise from its current state to an envisioned future state, to an envisioned future state, a process that requires a significant change in mindset, the adoption of a holistic view, and an execution to achieve the intended transformational goals and objectives. Transformation requires that you know the enterprise. You have to take a step back and look at the big picture. You need to gain a deep understanding of where things stand (Nightingale \& Srinivasn, 2011). 


\section{B. THE NAVAL AVIATION ENTERPRISE}

\section{Enterprise Framework}

The Naval Aviation Enterprise (NAE) is a partnership of key Naval Aviation stakeholders from the Navy and the Marine Corps. The Enterprise framework brings together the many parts that make up Naval Aviation in order to foster better decisionmaking that benefits Naval Aviation as a whole. By partnering in a collaborative manner, Naval Aviation is better able to produce warfighting readiness in the most cost-effective manner.

The Naval Aviation Enterprise derives its authority from NAVADMIN 204-06. In this NAVADMIN, the CNO identified the Navy's highest priority-to produce and deliver the most effective warfighting force to Combatant Commanders within the most efficient allocation of the Navy's resources.

“Naval Aviation's enterprise approach facilitates cooperation with other commands, the provider domains, and other organizations that impact Naval Aviation in order to improve the alignment of resources to achieve desired levels of readiness. The goal is an integrated approach to maximize readiness and efficiencies" (CNAF, 2012, p. 1). Figure 1 is an illustration of the NAE major stakeholders.

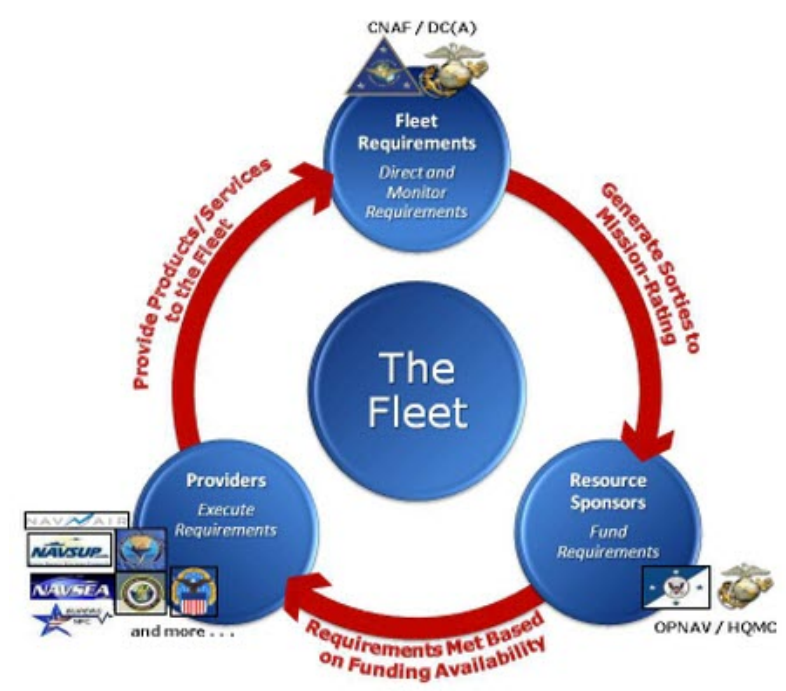

Figure 1. The Naval Aviation Enterprise (From: NAE, 2012) 


\section{Enterprise Guiding Principles}

An enterprise, and specifically the Naval Aviation Enterprise, is a way of doing business that promotes enhanced coordination and collaboration to achieve effectiveness, emphasizes the efficient use of resources, and provides information to aid in decisionmaking. Naval Aviation implements an enterprise approach based on the following principles:

1. Consistent cross-functional process thinking. Working horizontally across organizations, an enterprise can achieve desired results more effectively with less time and resources.

2. Process discipline. Dedicated, committed and coordinated efforts from stakeholder organizations will drive positive and predictable results.

3. Integrated, consistent and hierarchical metrics. Relevant measurements must be linked throughout the processes and must build on each other.

4. Full transparency of data, information and activities. Each piece of the enterprise must see the process ahead of it and the process behind it.

5. Accountability for actions and results. People within an enterprise hold themselves accountable for actions taken and not taken.

6. Integrated governance structure. Effective governance is adaptable to opportunities, inclusive and well-suited to work across boundaries and seams to sustain readiness.

7. Total ownership cost perspective. A strategic financial management view provides the ability to understand and manage affordability, while balancing risk and meeting operational requirements (CNAF, 2012). 


\section{NAVAL PILOT TRAINING}

\section{Pilot Training Pipeline}

All flight training begins at NAS Pensacola, Florida, the "Cradle of Naval Aviation.” Young men and women report from three recruiting sources: Just under 40\% come from the U.S. Naval Academy, just over 40\% come from Naval Reserve Officer Training Corps (NROTC) units, and just over 20\% from Officer Candidate School (OCS).

Navy, Marine Corps, Air Force and Coast Guard flight students spend about six weeks in Aviation Preflight Indoctrination (API) at the Naval Aviation Schools Command. Here they are challenged both academically and physically. Classes include: engineering, aerodynamics, air navigation, aviation physiology and water survival. Figure 2 is an illustration of the different Naval Aviation training tracks or "pipelines." The different phases of training are indicated in each box. This is a high level "value stream” map of Navy Pilot training. Each phase of training has internal corresponding value streams, which equate to curriculum event flow.
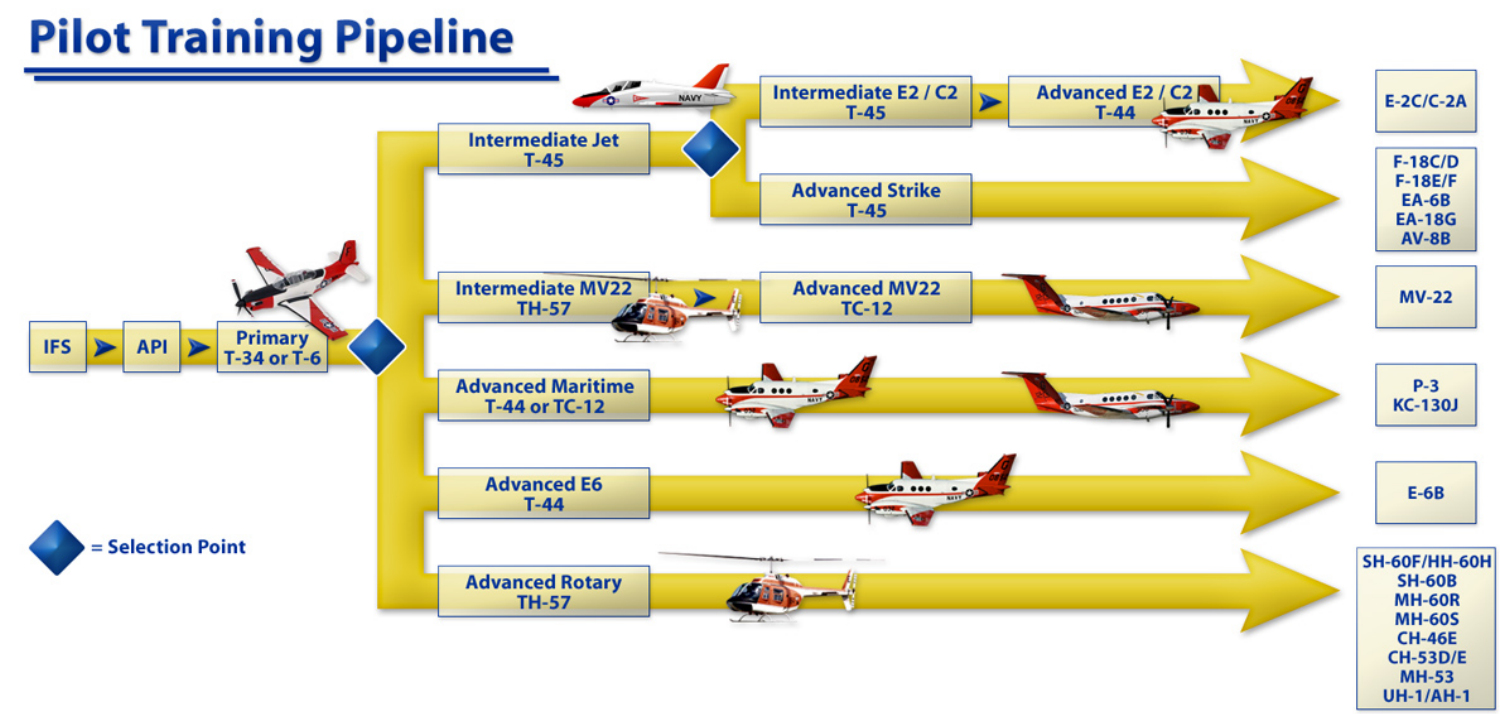

Figure 2. CNATRA Pilot Training Pipeline / Value Stream Map (From:

CNATRA, 2012) 
Upon completion of API, student pilots, also known as Student Naval Aviators (SNA), and student navigators, known as Student Naval Flight Officers (SNFO), proceed to their separate primary training pipelines. Primary SNA training is conducted at three bases: NAS Whiting Field, Milton, Florida, NAS Corpus Christi, Texas and Vance Air Force Base (AFB), Enid, Oklahoma. For the SNAs reporting to the Navy bases, primary training is approximately 22 weeks. It includes ground-based academics, simulators and flight training in either the T-34 Turbomentor or the T-6A Texan II. Primary training consists of six stages: Familiarization (FAM), Basic Instruments, Precision Aerobatics, Formation, Night FAM, and Radio Instruments.

Pipeline selections occur upon completion of primary training. This is based on the current and projected needs of the services, the student's performance and preferences. Student naval aviators are selected for: Maritime (multi-engine prop), E-2/C2, Rotary (helos), Strike (jets), and the E-6 TACAMO.

SNAs who enter the Strike (Jet) pipeline complete their training at either NAS Kingsville or at NAS Meridian in the T-45C. During Strike training, pilots learn strike tactics, weapons delivery, air combat maneuvering, and receive their carrier landing qualification. After receiving their Wings of Gold, Strike pilots report to an F/A-18, or EA-6B Fleet Replacement Squadron (FRS), and eventually report to their first Fleet squadron. Figure 3 is a map showing the locations of all the Navy's FRSs, which are the final step in the Naval Aviator training value stream.

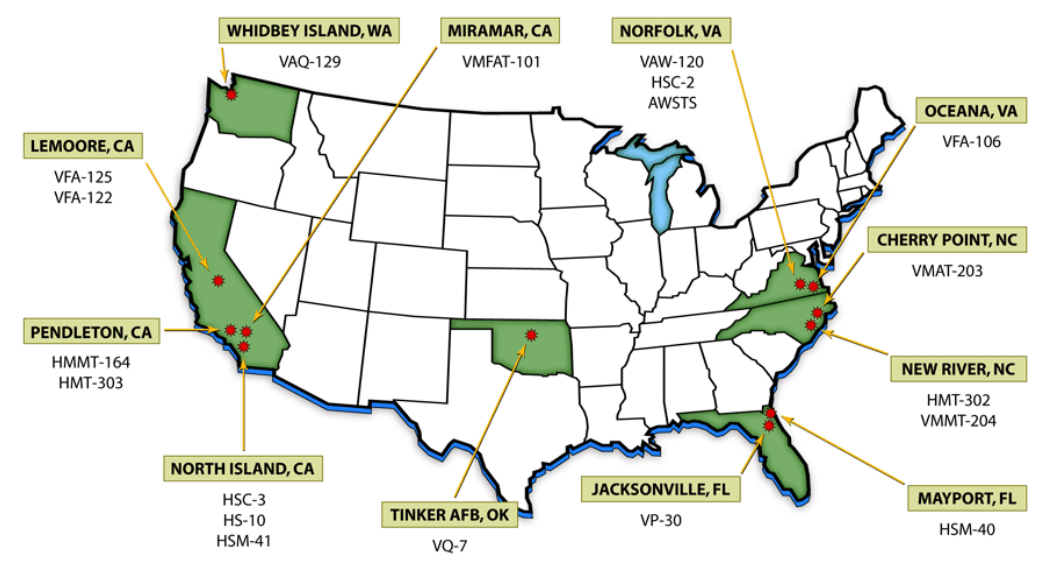

Figure 3. Fleet Replacement Squadron Locations (From: CNATRA, 2012) 
Naval Aviation training is a significant part of the total Naval Aviation Enterprise. "In 2009, CNATRAs 739 aircraft logged 358,449 flight hours, nearly a third of the Department of the Navy total. To put those numbers in perspective, CNATRA commands flew $28 \%$ of the combined Navy and Marine Corps flight hours with $19 \%$ of the aircraft. In that same time more than 2,400 pilots, Naval Flight Officers (NFO) and Aircrew earned their Wings of Gold" (CNATRA, 2012).

\section{BEGINNINGS OF LEAN IN NAVAL AVIATION TRAINING}

\section{Naval Aviation Production Process Improvement Program}

In the late nineties, it was apparent the Navy had under assessed the number of pilots it would need to meet fleet demand. FRS (Fleet Replacement Squadron) Class sizes were down, and fleet demand had remained constant. Under accession of 26 Replacement Pilots (RPs) in the 1993 to 1996 year groups led to first tour lengths increasing to 43 months (target first tour length was 36 months). Additionally, TACAIR (Tactical Air) pilots were averaging about 4 years to get to the fleet and helicopter pilot averages had increased to over 2.5 years. Naval aviation was at a critical juncture as it strived to stabilize its air force and rebuild the depth in its junior officer ranks (N88, 2000).

In 1998 the Naval Aviation Production Process Improvement (NAPPI) program was started under the direction of OPNAV N88 to improve Fleet Replacement Squadron (FRS) output of first tour aviators (pilots and NFOs) in the Navy and Marine Corps. Senior Naval Aviation Leadership, guided by N88, defined NAPPI objectives:

- $\quad$ Reduce Aviator Time-To-Train (TTT), from commissioning to completing the last event in the FRS to 17 to 35 months depending on specific pipeline.

- The annual Naval Aviator output must meet fleet requirements in sufficient numbers to ensure a three-year first sea tour. This will require training approximately one third of first-tour fleet aviators each year. 
Since implementation, the NAPPI program has made significant improvements in TTT and production management. The process has matured to the point where it is now in the sustainment phase and expanded to include Naval Aircrew and Production of CAT Other aircrew at the FRSs, and is referred to as the Naval Aviator Production Process (NAPP). The following area are actively managed as an on-going part of the NAPP:

- $\quad$ Major and Sub-Process Command and Control

- Measurements, including all process metrics and linkage between processes

- $\quad$ Student inventory or pool sizes and locations

- $\quad$ Resource allocation and balancing

- $\quad$ Task evaluation and prioritization in each production process

- $\quad$ Planning and scheduling methods across and within each process (Sizemore, 2010).

\section{Naval Aviation Enterprise AirSpeed Program}

The transformation of Naval Aviation's logistics chain began as the brainchild of Marines stationed in Iwakuni, Japan who were inspired to improve their command's maintenance processes by a book published almost 15 years before.

In 1998, Marine Aviation Logistics Squadron 12 (MALS-12) was no different than any other intermediate maintenance activity when it came to fixing aircraft-they managed a system flooded with work in progress, routinely performed expeditious repairs, performed multiple iterations of repairs and cannibalized equipment from one aircraft to put in another. Maintenance and supply were not aligned and processes were not standard. What they had is what was fixed and then pushed out to the squadrons.

After reading The Goal, Marines of MALS-12 believed they could apply the Theory of Constraints (TOC) to their work centers and improve service to the warfighter. Armed with the basic knowledge of the methodology, the Marines adopted TOC. And they got results. Their improved ability to meet flight line demand captured the attention 
of then Rear Adm. Wally Massenburg, assistant commander for Logistics and Industrial Operations at Naval Air Systems Command (NAVAIR), who was eager to replicate their successes throughout Naval Aviation. That recognition spurred the adoption of better business practices by several aircraft intermediate maintenance activities (IMA) and MALS and helped transform Naval Aviation's culture into one of cost-wise readiness. At the same time, aviation maintenance activities at Naval Air Station (NAS) Lemoore, and later NAS Oceana, began to use Lean to improve their processes. And NAVAIR Depot Cherry Point began to use TOC.

In 2001, a joint ASL/NAVAIR team stood up the Relevant Information For Leadership (RIFLe) program; North Island was the first to undergo RIFLe implementation using Basic TOC. This initiative later expanded first into Depot AIRSpeed and then, in 2003, evolved into Enterprise AIRSpeed. IMAs at NAS Oceana, NAS Lemoore and MALS-31 in Beaufort were among the first to undergo formal Enterprise AIRSpeed implementation.

Meanwhile, in 2004, six squadrons participated in a seven-week organizationallevel maintenance CPI pilot program. Helicopter Anti-Submarine Squadron 10, Patrol Squadron 46, Fleet Logistics Support Squadron 30, Electronic Attack Squadron 129, Helicopter Sea Combat Squadron 3 and Strike Fighter Squadron 122 each tackled a different aircraft ready for tasking issue specific to their type/model/series (TMS).

Naval Aviation Enterprise leadership recognized the need for CPI to be seamless throughout Naval Aviation and authorized the introduction of AIRSpeed toolsets into aircraft intermediate maintenance departments aboard aircraft carriers in 2005.

USS John C. Stennis (CVN 74) was selected to prototype Enterprise AIRSpeed implementation aboard aircraft carriers in 2006 to capture the investment and requirements needed to replicate the process. Today, CPI training aboard aircraft carriers has been condensed into a three-week implementation due to ships' deployment and maintenance schedules. Enterprise AIRSpeed also is providing training to Marines and Sailors assigned to L-class ships, USS Peleliu (LHA 5) being the first in July 2009. 
Another initiative spurred by the success of MALS-12 and in light of the warfighters' demands in Iraq and Afghanistan is the Marine Aviation Logistic Support Program (MALSP) II. The same Marines who had introduced TOC in Iwakuni, Japan, saw how TOC and other methodologies could be applied in an expeditionary environment.

MALSP II was stood up in 2004 after Operation Iraqi Freedom and Operation Enduring Freedom proved MALSP to be inefficient and revealed the need for a more seamless, proactive, agile, dynamic, and flexible system that controls variability, takes into account interdependencies, and reduces bottlenecks. MALSP II will support Sea Basing and expeditionary maneuver warfare through significantly reduced logistics footprint forward. In 2005, the Patriots of MALS-26 began to pilot MALSP II at $\mathrm{Al}$ Asad, Iraq. The team continues to prototype MALSP II forward deployed.

Current Readiness End-to-End (CR E2E) AIRSpeed was rolled out in 2007 to synchronize activities at the operational, intermediate, and depot maintenance and supply levels to facilitate a squadron's ability to "pull" logistics support across the chain to meet flight line demand. The KC-130 community was the first TMS to apply CR E2E AIRSpeed. In 2010, the AV-8B community became the second TMS to do so.

In 2008, Maintenance \& Supply Integration Performance Improvement Branch’s (MSIPIB) was stood up to more accurately reflect its core purpose of improving logistics chain management. The MSIPIB includes Enterprise AIRSpeed, MALSP II and CR E2E AIRSpeed.

Currently, efforts are underway to more closely align with other Naval Aviation CPI initiatives-Naval Air Systems Command AIRSpeed, Fleet Readiness Center AIRSpeed, and Depot AIRSpeed. The term "AIRSpeed" will continue to refer to the family of Naval Aviation Enterprise's CPI activities (CNAF, 2012). Figure 4 illustrates the progression of the Naval Aviation Enterprise's AirSpeed program. 


\section{Naval Aviation Enterprise AIRSpeed}

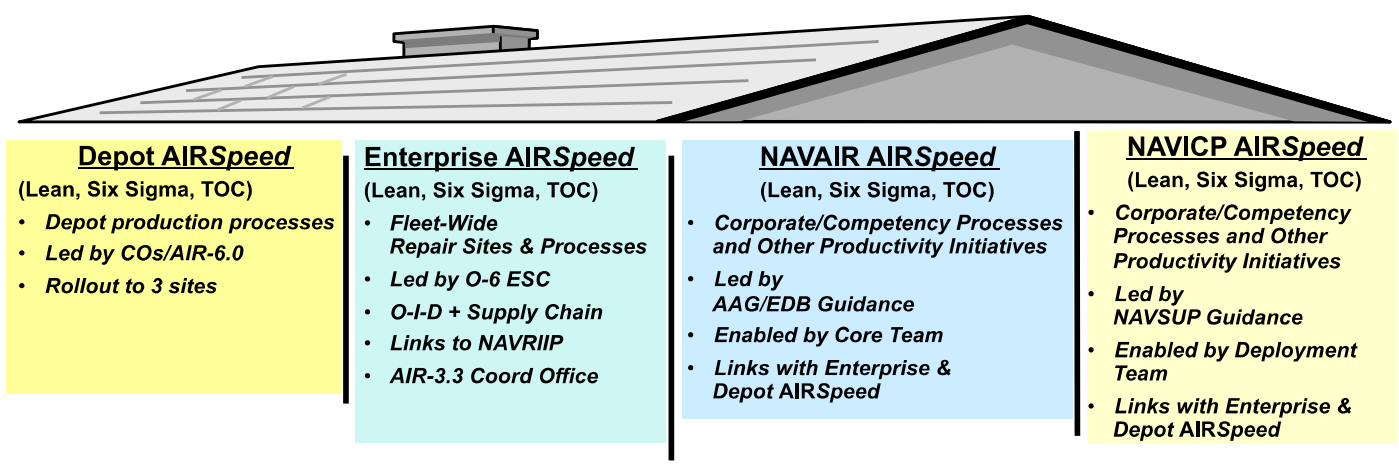

- There are FOUR AIRSPEED programs with One Goal and One Metric:

- Depot AIRSPEED which began in 1999

- Enterprise AIRSPEED which began in 2003

- NAVAIR AIRSPEED which began in 2004

- NAVICP AIRSPEED which began in 2005

- All four drive productivity through process improvement using industry-proven tools, and help establish a self-sustaining culture of continuous improvement.

Figure 4. History of AIRSpeed (From: Moore, 2007)

\section{Naval Aviation Enterprise Lean Training Transformation}

On March 9, 2006, the Chief of Naval Operations (CNO) approved the alignment of CNATRA under Commander, Naval Air Forces (CNAF), to be effective in Fiscal Year (FY) 2007. The goal of this alignment is to fully leverage the core competencies of both Manpower, Personnel, Training \& Education (MPT\&E) and the Naval Aviation Enterprise (NAE) in the production of aircrew. The arrangement improves the NAE span of control over naval aviator and aircrew production and aircraft, allowing better management of aviator production capacity within the Fleet force structure, while aligning CNATRA’s approximately 725 aircraft within the Naval Air Force. By setting up student "Street to Seat" under MPT\&E and "Seat to Fleet" under the NAE, efficiencies will be gained in standardization of Production Planning Factors, alignment of Fleet Replacement Squadron (FRS) and Training Command (TRACOM) curricula, and the potential download of training hours from more expensive cost-per-hour FRS 
aircraft to less expensive TRACOM aircraft. Under this construct, CNATRA's budget will shift from training resources to readiness resources, allowing rapid shift of training down to the lowest cost asset, providing the greatest training benefit at the lowest possible cost (CNATRA, 2007, p. 4).

Figure 5 shows all the process stakeholders in the Naval Aviation Enterprise and how Navy leadership is moving towards a more Lean Enterprise construct.

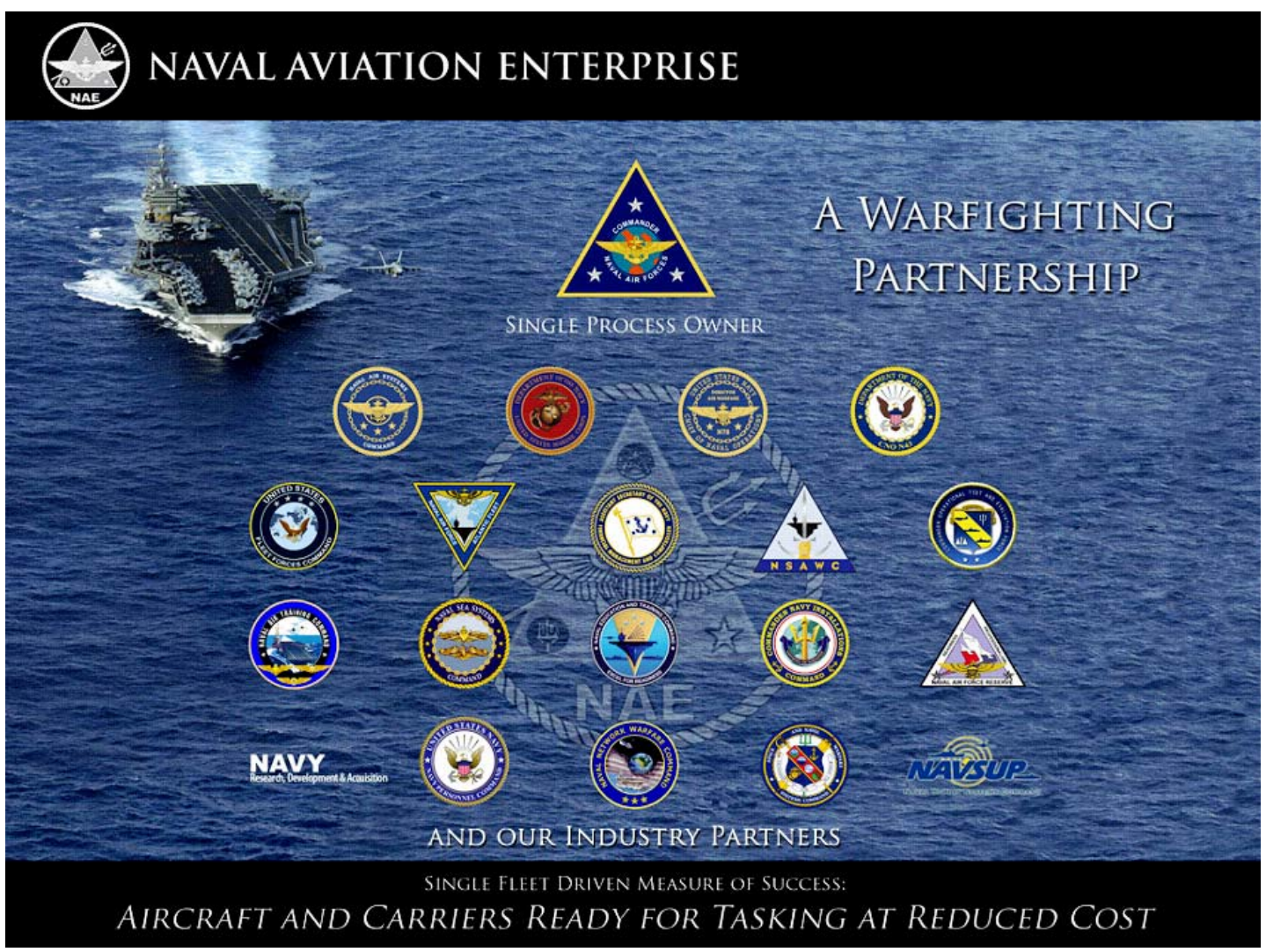

Figure 5. Naval Aviation Enterprise (From: Moore, 2007) 
THIS PAGE INTENTIONALLY LEFT BLANK 


\section{DATA}

\section{A. SPECIFY VALUE IN TRAINING}

\section{How do you define value in Naval Aviation training?}

According to Lean thinking, value can only be defined by the ultimate customer. As in all government organizations defining who the customer is can be very difficult, it can be argued that the taxpayer is the ultimate customer. For the purposes of this project the customer will be defined as the Fleet and Unified Commanders. So what value does the Commander, Naval Air Forces attempt to provide to Fleet and Unified Commanders? “The Naval Air Forces' mission is to man, train, equip and maintain a Naval Air Force that is immediately employable, forward deployed and engaged. We support the Fleet and Unified Commanders by delivering the right force with the right readiness at the right time with a reduced cost... today and in the future” (CNAF, 2012).

Commands within the training value stream attempt to define value in each of their mission statements. The Mission of Naval Air Training Command is to train the world's finest combat quality aviation professionals, delivering them at the right time, in the right numbers, and at the right cost to the Joint Forces for tasking in the Global War on Terrorism (CNATRA, 2012). VFA-106, the largest of the Navy's Hornet Fleet Replacement Squadrons, mission is to train and prepare the finest Strike Fighter Aircrew and Maintenance Professionals for the Fleet and the Fleet Marine Force in support of combat operations around the world (VFA-106, 2012). VT-7, one of the Navy's four Advanced/Intermediate Jet training squadron, has a mission to safely and effectively train the world's finest Naval Aviators and preparing them for service and success in the Fleet (VT-7, 2012). VT-3, one of the Navy's six primary flight training squadrons, mission is to provide intensive, joint primary flight training for Air Force, Coast Guard, Navy, Marine Corps, and Allied flight students in the following courses of instruction: Contact Flight, Basic Instruments, Precision Aerobatics, Formation, Night Flight, and Radio Instruments (VT-3, 2012). 
The Navy Combined Jet curriculum guide provides more detailed information on what is valued in the training of a Naval Aviator. The overall goal of the T-45 Combined Flight Training curriculum is to establish a finite airmanship capacity such that graduates can readily adapt to fleet carrier-based aircraft operations. The objective is achieved through the development of tactical flying skills and judgment at a steady increase in mission task loading. On completion, the Student Naval Aviator (SNA) will have demonstrated the following airmanship skills:

- $\quad$ Flight Preparation and Planning

o Preparation. Demonstrate understanding of aerodynamics, meteorology, flight physiology, navigation, communication, aircraft performance, and aircraft systems management.

o Planning. Plan each flight event in terms of communication, navigation, weapons system management, flight leadership, and aircraft control requirements. Demonstrate the in-flight ability to execute the preflight plan and respond to airborne contingencies.

- $\quad$ Aircraft Control

o Control the aircraft dual or solo, day and night, under various meteorological conditions.

o Maintain the T-45 within the g, angle-of-attack (AOA), and airspeed envelopes; ensure safe aircraft-to-ground and aircraft-to-aircraft separation; and control the aircraft flight vector to meet mission performance standards.

- $\quad$ Mission Control

o Navigation. Maintain aircraft position within a desired geographical area or along a specific ground track using visual cues, aircraft-installed electronic equipment, aeronautical charts, voice communications with controlling agencies and dead reckoning techniques while complying with appropriate regulations and standard operating procedures. 
o Communications. Communicate clearly with ground agencies and other aircraft using approved radio terminology and aircraft electronic transmitting equipment as well as light, hand, or aircraft maneuvering signals.

o Systems Management. Manage aircraft flight, navigation, communications, and weapons delivery systems in primary and degraded modes as required for successful mission completion.

o Flight Leadership. Display the potential for future designation as section/division leader by demonstrating the ability to brief a flight event, execute the mission plan as flight lead or wingman, and debrief the results in terms of mission objectives and performance standards. Demonstrate basic fundamentals of "mutual support," "teamwork," and "aircrew coordination" during multi-plane events.

o Tactical Missions. Demonstrate ability to integrate basic aircraft handling, takeoff and landing, formation, and instrument flying skills with mission support skills above.

- Expand basic aircraft and mission control skills during execution of airways instrument navigation, carrier qualification, low-level navigation, air-to-ground weapons delivery, and air combat maneuvering exercises.

Situational Awareness. Demonstrate the ability to control the frequency and duration of time available for mission tasks relative to aircraft control tasks. Display the ability to remain continuously oriented within the flight's environment and to correctly analyze factors, which will affect the successful completion of the task at hand. 
- $\quad$ Crew Resource Management (CRM). Demonstrate the ability to employ effective CRM concepts and activities in all phases of flight training and mission tasking to permit accomplishment of training goals (Crabbe, 2011).

\section{B. TRAINING VALUE STREAM}

How do you identify and integrate management of the entire Naval Aviation training value stream?

A value stream has two forms, the first an internal sequence of activities that must be combined to create a product or service (the internal value stream) and the second is concerns the business, its customers and its suppliers (supply chain value stream) The internal value stream therefore contains all the assets, people and processes to manufacture products. 


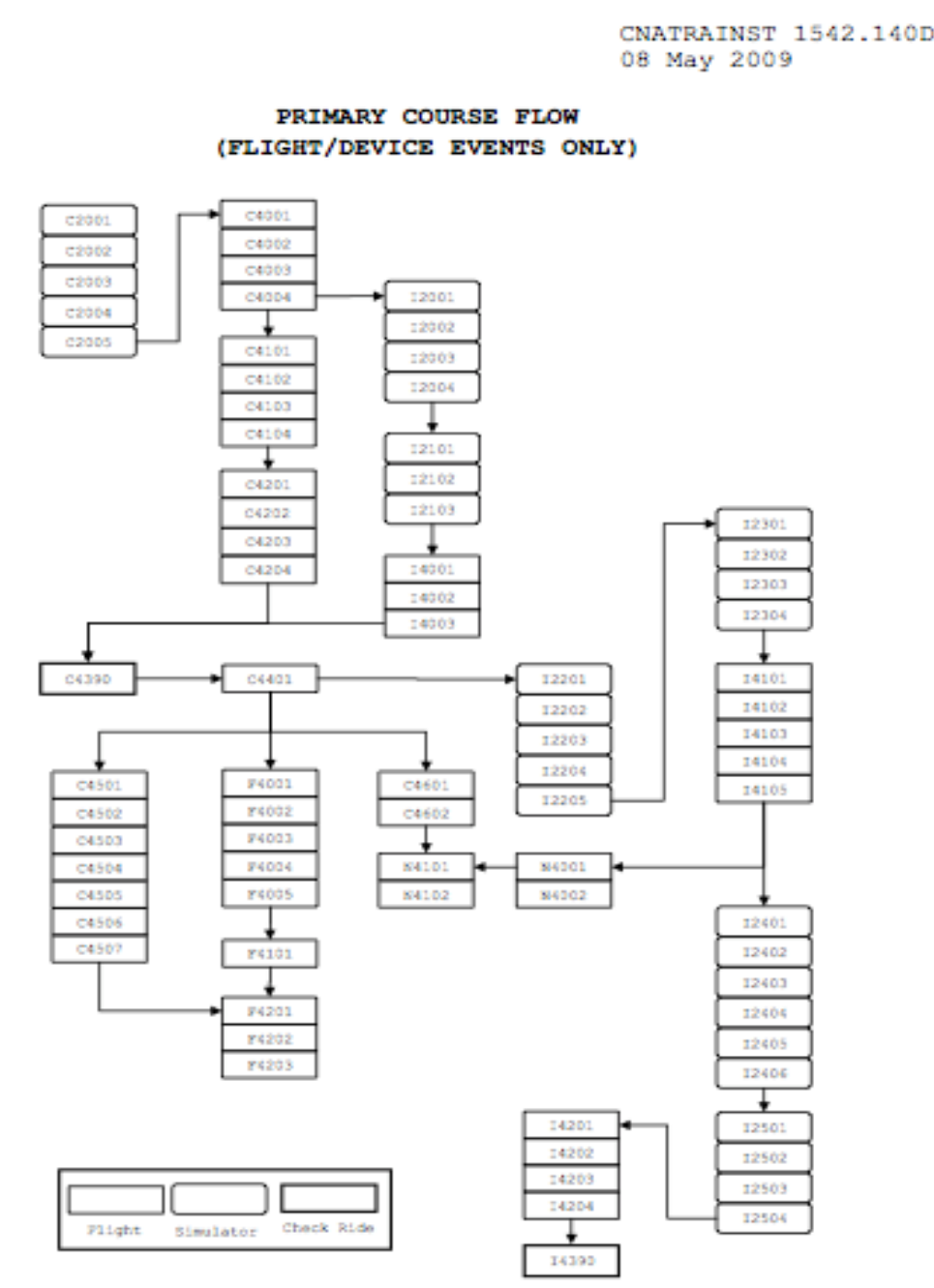

Figure 6. Internal Primary Value Stream (From: Crabbe, 2011)

Figure 6 is a Primary flight training course flow, which equates to a portion the total internal value stream for Navy flight training. Each rectangle represents one flight or simulator. C---- events are aircraft familiarization blocks, F---- events are formation flying blocks, and I----- events are instrument events. This particular course flow map allows for several different flow options based on prerequisites that have been met. Figure 7 shows how many hours/flights are programed into each type of flight training event during Primary flight training. Total hours and events are shown for Cockpit Procedures Trainer (CPT), Simulator (SIM), and the T-34C aircraft. Correlating information in Figures 6 and 7 can be used to generate a functional value stream map. 


\begin{tabular}{|c|c|c|c|c|c|c|c|c|}
\hline \multicolumn{9}{|c|}{ INITIAL FLIGHT TRAINING } \\
\hline \multirow[b]{2}{*}{ Flight/Events } & \multirow{2}{*}{\multicolumn{2}{|c|}{ CPT }} & \multirow{2}{*}{\multicolumn{2}{|c|}{ SIM }} & \multicolumn{4}{|c|}{$T-34 C$} \\
\hline & & & & & $\begin{array}{r}\text { Du } \\
\text { Flts }\end{array}$ & Hrs & $\begin{array}{l}\text { Sol } \\
\text { Flts }\end{array}$ & $\begin{array}{l}\text { Ho } \\
\text { Hrs }\end{array}$ \\
\hline Cockpit Procedure & 5 & 6.5 & & & & & & \\
\hline Day Contact & & & & & 16 & 29.2 & 4 & 6.9 \\
\hline Day Contact Check & & & & & 1 & 2.0 & & \\
\hline Night Contact & & & & & 2 & 3.0 & & \\
\hline Basic Instruments & & & 7 & 9.1 & 3 & 4.5 & & \\
\hline Radio Instruments & & & 9 & 11.7 & 5 & 9.0 & & \\
\hline $\begin{array}{l}\text { Instrument } \\
\text { Navigation }\end{array}$ & & & 10 & 13.0 & 4 & 8.0 & & \\
\hline Instrument Check & & & & & 1 & 2.0 & & \\
\hline Day Navigation & & & & & 2 & 3.2 & & \\
\hline Night Navigation & & & & & 2 & 3.2 & & \\
\hline Basic Formation & & & & & 5 & 10.5 & 1 & 1.5 \\
\hline Cruise Formation & & & & & 3 & 6.0 & & \\
\hline Totals & 5 & 6.5 & 26 & 33.8 & 44 & 80.6 & 5 & 8.4 \\
\hline
\end{tabular}

Figure 7. $\quad$ Primary Flight Training Programed Flights/Hours (From: Crabbe, 2011)

“The supply chain value stream includes every organization that must combine to produce the final product offered to the customer and these value streams need to be structured and controlled in order to optimize the material flow throughout the entire chain” (Rich, 2001, p. 3).

The NAPP attempts to address both internal and external value streams. The goal of the Naval Aviator Production Process is centered on meeting the annual fleet requirements as defined by the Integrated Production Plan (IPP) from initial accession to completion of FRS training. Aviator Production Planning is the process used to establish and manage the flow of aviators from accession to the fleet. The result of this process is an optimized total time-to-train for all pilots, NFOs, and NAC by linking each training phase to the next within each production pipeline. The previous Figure 3 is an example of the overall supply chain value stream for Naval Aviation training.

CNATRA Headquarters develops the Integrated Production Plan (IPP), which details production requirements from the FRSs back to the Wing and schoolhouse level on a monthly basis. The IPP is based on Fleet requirements for replacement Naval 
Aviators and NAC, production capacities and pipeline phase TTT. The Strike/Fighter FY 11/12 IPP for FRS and CNATRA production is illustrated in Figure 8. As of September 2012 there is a forecast deficit of 31 pilots leaving the FRSs. The CNATRA IPP production chart is forecasting excess production of 20 students leaving the training commands by the end of FY12.

\begin{tabular}{|c|c|c|c|c|c|c|c|c|c|c|c|c|c|c|c|c|c|c|c|c|c|c|c|c|c|c|}
\hline \multicolumn{14}{|c|}{ FRS Production } & \multicolumn{13}{|c|}{ FRS Production } \\
\hline \multicolumn{14}{|c|}{2011 - Total All } & \multicolumn{13}{|c|}{2012 - Total All } \\
\hline & 0 & $\mathrm{~N}$ & $D$ & $\mathrm{~J}$ & $F$ & $M$ & A & $M$ & J & $J$ & A & 5 & Total & 0 & $\mathrm{~N}$ & D & $\mathrm{J}$ & $F$ & $M$ & A & $M$ & 1 & $\mathrm{~J}$ & A & 5 & Total \\
\hline Planned Ins & 16 & 23 & 5 & 27 & 25 & 12 & 23 & 35 & 21 & 3 & 21 & 29 & 240 & 19 & 15 & 7 & 25 & 8 & 27 & 4 & 29 & 20 & 27 & 9 & 23 & 213 \\
\hline Class Load & 22 & 34 & 0 & 18 & 30 & 8 & 30 & 35 & 21 & 6 & 20 & 28 & 252 & 19 & 21 & 8 & 9 & 8 & 36 & 4 & 29 & 19 & 0 & 29 & 21 & 203 \\
\hline Fleet Requirement & & & & & & & & & & & & & 240 & & & & & & & & & & & & & 225 \\
\hline FRS Plan Out & 12 & 35 & 10 & 19 & 11 & 23 & 21 & 31 & 27 & 15 & 26 & 10 & 240 & 18 & 25 & 4 & 33 & 21 & 12 & 22 & 11 & 18 & 28 & 7 & 26 & 225 \\
\hline Actual Out & 15 & 21 & 10 & 25 & 2 & 22 & 15 & 14 & 2 & 23 & 46 & 32 & 209 & 20 & 22 & 20 & 9 & 29 & 17 & 16 & 8 & 19 & 15 & 21 & 2 & 167 \\
\hline Projected Out & & & & & & & & & & & & & 209 & & & & & & & & & & & & 27 & 194 \\
\hline Excess/Deficit Cum & -15 & -29 & -29 & -23 & -32 & -33 & -39 & -56 & -81 & -73 & -53 & -31 & -31 & -29 & -32 & -16 & -40 & -32 & -27 & -33 & -36 & -35 & -48 & -34 & -31 & -31 \\
\hline FY Carryover & -18 & & & & & & & & & & & & & -31 & & & & & & & & & & & & \\
\hline
\end{tabular}

\begin{tabular}{|c|c|c|c|c|c|c|c|c|c|c|c|c|c|c|c|c|c|c|c|c|c|c|c|c|c|c|}
\hline \multicolumn{14}{|c|}{ CNATRA Production } & \multicolumn{13}{|c|}{ CNATRA Production } \\
\hline \multicolumn{14}{|c|}{2011 - Total All } & \multicolumn{13}{|c|}{2012 - Total All } \\
\hline & 0 & $\mathrm{~N}$ & $D$ & J & $\mathrm{F}$ & $M$ & A & $M$ & J & J & A & S & Total & 0 & $\mathrm{~N}$ & D & J & $F$ & $M$ & A & $M$ & J & J & A & s & Total \\
\hline Planned Ins & 25 & 16 & 22 & 10 & 19 & 36 & 14 & 28 & 22 & 14 & 25 & 11 & 242 & 37 & 28 & 0 & 37 & 14 & 17 & 43 & 11 & 13 & 32 & 26 & 19 & 277 \\
\hline Class Load & 22 & 18 & 19 & 15 & 31 & 19 & 18 & 27 & 21 & 14 & 23 & 22 & 249 & 15 & 15 & 1 & 20 & 20 & 25 & 38 & 16 & 30 & 21 & 12 & 13 & 226 \\
\hline Required Out & 20 & 30 & 12 & 22 & 28 & 23 & 19 & 22 & 11 & 25 & 29 & 16 & 257 & 24 & 19 & 16 & 16 & 16 & 24 & 20 & 17 & 29 & 15 & 30 & 14 & 240 \\
\hline CNATRA Plan Out & 10 & 33 & 24 & 13 & 33 & 25 & 16 & 22 & 10 & 17 & 38 & 13 & 254 & 30 & 17 & 14 & 18 & 16 & 35 & 24 & 0 & 37 & 14 & 17 & 21 & 243 \\
\hline Actual Out & 13 & 28 & 23 & 10 & 32 & 15 & 25 & 35 & 5 & 0 & 45 & 13 & 250 & 35 & 4 & 27 & 1 & 24 & 38 & 10 & 9 & 36 & 17 & 18 & 3 & 227 \\
\hline Projected Out & & & & & & & & & & & & & 250 & & & & & & & & & & & & 15 & 242 \\
\hline Adjustment & 12 & 0 & 0 & 0 & 0 & 0 & 0 & 0 & 0 & 0 & 0 & \begin{tabular}{l|l}
-3 \\
\end{tabular} & 9 & 11 & 0 & 0 & 0 & 0 & 0 & 0 & 0 & 10 & 0 & 0 & 0 & 21 \\
\hline Excess/Deficit Cum & 21 & 16 & 15 & 12 & 11 & 1 & 10 & 23 & 18 & 1 & 8 & 5 & 5 & 21 & 8 & 21 & 4 & 12 & 15 & 1 & 10 & 19 & 22 & 23 & 20 & 20 \\
\hline FY Carryover & 6 & & & & & & & & & & & & & 5 & & & & & & & & & & & & \\
\hline
\end{tabular}

Figure 8. Spring 12 Strike/ Fighter Integrated Production Plan

Production Planning Factors (PPFs) incorporate all factors affecting a squadron's production resources; i.e., instructor manning, aircraft available, and flight hour program; and are used to calculate student production capacity. If the squadron's production capacity is less than the IPP requirement, either the IPP will be reduced to reflect the lower production goal or steps to remove the barrier to student production will be implemented to meet IPP requirements. (Sizemore, 2010, p. 35)

Figure 9 is an illustration of the NAPP management process flow. The management process flow is iterative in nature based on fleet pilot demands and production capacity. Production gaps are analyzed using the production tools and the barriers to production are addressed at the appropriate level. 


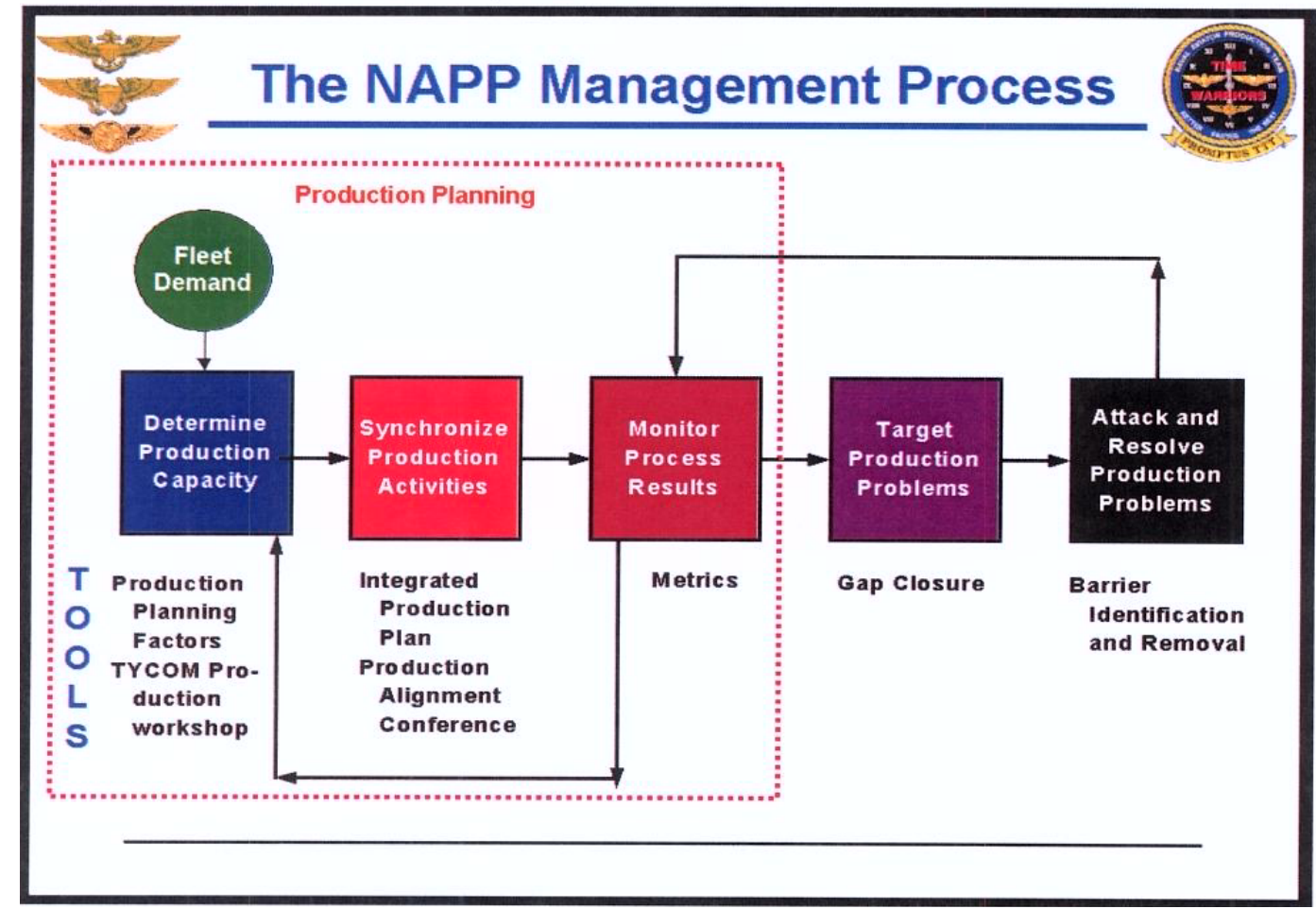

Figure 9. The NAPP Management Process, (From: Sizemore, 2010)

\section{TRAINING FLOW}

How do you design a production training systems that ensure training flows?

In order for training production to flow wastes must be eliminated. Taiichi Ohno, the designer of the Toyota Production System, was obsessed with making materials flow and to assist in this process he developed seven classifications of waste in manufacturing facilities. These seven examples of manufacturing waste can directly correlate to waste in aviation training:

- Overproduction.-Overproduction of pilots between phases of training.

- Unnecessary stocks. -Student pooling between phases or blocks.

- Producing quality defects. Delays (waiting).-Varying scheduling priorities for students during different blocks of training.

- Unnecessary transport.-Multiple moves between training phases. 
- Inappropriate processing.-Using high cost training assets where lower cost assets could provide similar value added.

- Unnecessary motion.-No value added redundant training events.

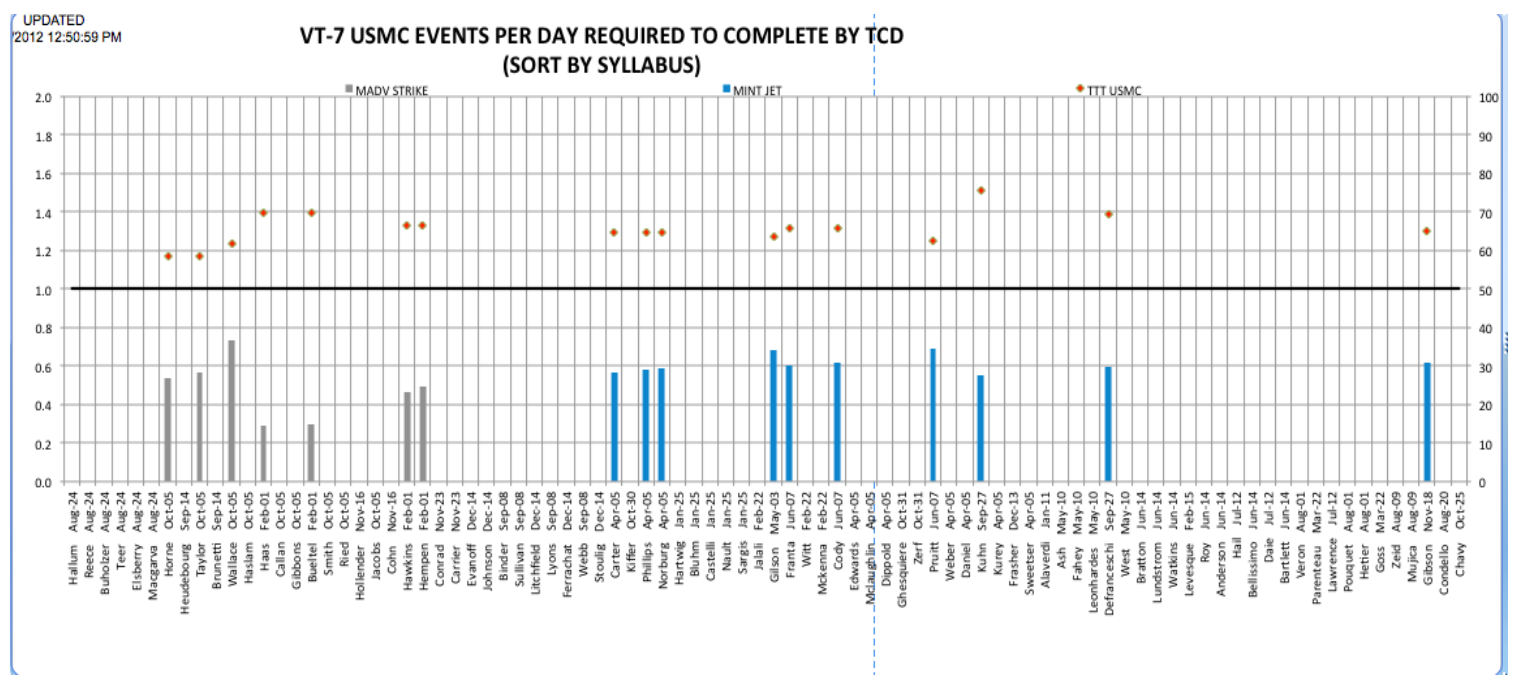

Figure 10. VT-7 USMC Events Per Day Required

Figure 10 is an example of a chart that is used by squadron operations. This chart shows the daily status of USMC students. The $\mathrm{X}$ axis annotates individual student names and their planned completion date. The left $\mathrm{Y}$ axis indicates the total events per day required per student. Flights, simulators or lectures all count as an event. The right $\mathrm{Y}$ axis shows the percentage of Total-Time-to-Train indicated by the red diamond. The solid gray line indicates one event per day, which is the optimal for current production requirements. This data can be used to determine the potential for unnecessary stock, quality defects, and/or delays. Figure 10 indicates that USMC students are being scheduled at less than an optimal level, which leads to quality defects or less consistent learning. The less than optimal event per day requirement indicates an unnecessary stock of USMC students. They are currently not flowing through the VT-7 curriculum.

"To flow materials properly, at low cost, requires the quality of the material to be completely assured or you simply move defects around the factory quicker and end up 
with more chaos. Conversely, speeding up machines may not provide the greatest return for manufacturers if the output of these machines languishes in huge stockpiles" (Rich, 2001, p. 4).

In February 2010, during an inspection, a plane captain at Naval Air Station Whiting Field discovered a crack in the rudder pedal bracket assembly of a T-34 primary aircraft and reported the problem to the Maintenance Department. As more aircraft were inspected, similar cracks were found. Naval Air Systems Command issued a bulletin grounding all T-34s aircraft until inspected and corrected. Over two-thirds of the aged aircraft were adversely affected and, for nearly two months, primary training came to a halt. As the primary production machine began to recover, the need to accelerate training in order to make up for the lost production days became critical not only to the primary phase of training but also to all downstream intermediate and advanced stages.

Numerous action plans were initiated to accelerate training. But with each effort, it seemed second and third order negative effects became barriers to efficient student flow. It took more than a year to return to the primary production baseline and many painful and costly lessons were learned during these surge operations.

To prepare better for future situations like this, the Chief of Naval Aviation Training (CNATRA) and the Naval Air Systems Command hired Dallas-based Lone Star Aerospace to build a mathematical model of the entire training enterprise. This computer model contains more than 2,300 elements that represent the complete undergraduate naval aviator training. (Supple, 2012, p. 1)

\section{TRAINING PULL} needs?

How do you introduce a pull training production system to support customer

The use of pull techniques allows lead times to be reduced and improves the flow of materials within and between organizations. The application of pull production on a supply stream scale means that material flow, throughout the entire population of suppliers, can be employed to increase the synchronicity of manufacturing products to order rather than the best guessing involved with most forecasts that are by nature inaccurate and inflated (Rich, 2001). 
The NAPP program has implemented pull techniques to improve flow of Naval Aviation training.

OPNAV N88 is responsible for determining the annual "Fleet Requirement" for all Categories of Navy and Marin aviators based on annual operational squadron manning requirements as adjusted by CNO/USM manning policies, known or projected force structure changes, and relevant personnel actions. N88 publishes the multi-year Training Requirements Letter (TRL), which delineates FRS training requirements. This letter forms the basis for the annual capacity determinations through Production Planning Factors (PPF), and IPP development. Once the IPP is completed and approved, it is forwarded back to N88 in order to determine the ability of the NAPP to meet the stated Fleet requirement and allow N88 to react to projected shortfall or surpluses in annual aviator production. N88 coordinates with appropriate OPNAV offices to ensure production barriers limiting available NAPP production below fleet requirements are escalated as appropriate or addressed through the Program Objective Memorandum (POM) and budgetary process. (Sizemore, 2010)

Figure 11 illustrates the Naval Aviation Enterpise pull process and all of its stakeholders. A large part of the NAPP process is the Production Alignment Conference, which allow a direct dialogue between requirements (fleet customer) and production units (value stream).

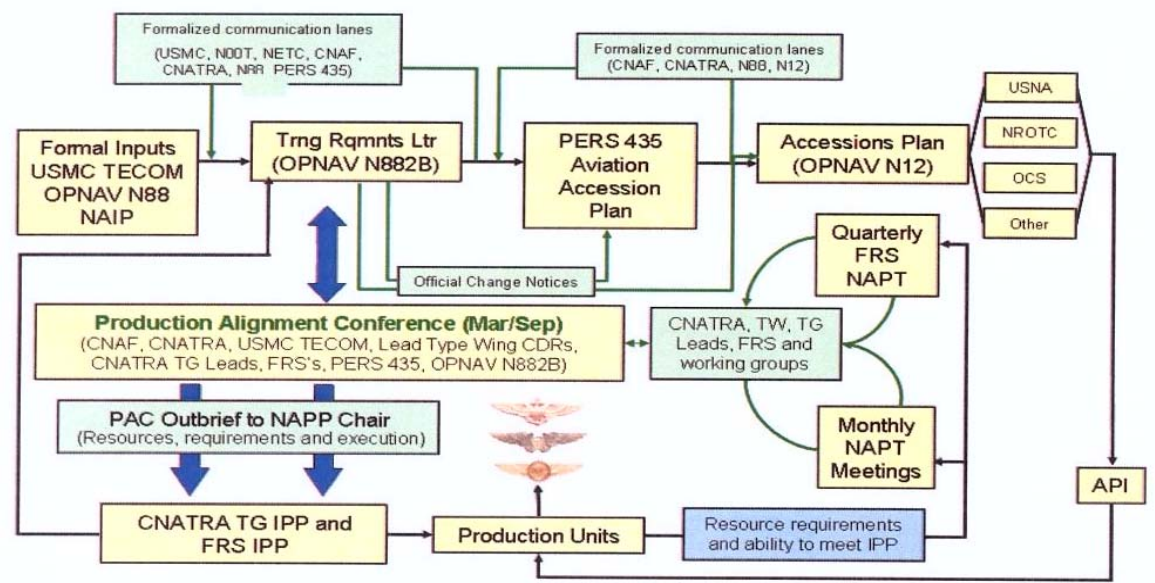

Figure 11. NAPP Pull Requirements Flow Chart (From: Sizemore, 2010) 


\section{E. TRAINING PERFECTION}

\section{How do you continuously improve all business activities to achieve perfection in training?}

In lean organizations the number of ways in which the employees can contribute to the improvement of activities and the performance of the firm is much greater than the traditional forms of employee integration. The lean approach goes far beyond the suggestions scheme and includes a lifetime of continuous improvement by every worker, by every manager and by every supplier upon whom the lean plant is dependent. Within this context, improvement ideas flow-safe in the knowledge that people will not be made redundant as a result of a given improvement (but they may be reassigned within the firm) (Rich, 2001).

CNATRA has policy is in place for recommendations of improvements to the training curriculums. All training command personnel are part of the CNATRA Training program Improvement Team and should provide suggestions to improve each course of instruction when necessary. It is the input from each instructor and student involved with the day to day execution of student naval aviator training which will ensure the NATRACOM continues to train aviators based on lessons learned and known best practices (CNATRA, 2003).

Further steps are being performed in order to achieve perfection in production. PMA-273 (Capt. Hartigan, The program manager for the Naval Undergraduate Flight Training Systems Program Office) hosted three industry days to solicit the expertise of the industry providers who perform Contractor Logistics Support work.

These industry inputs and performance-influencing variables were then modeled using a sophisticated enterprise simulation to provide decision quality guidance on how to optimize cost and performance through NAVAIR sustainment contracts with CLS providers "The simulation considers over 200 variables, such as contract type, incentive structure, performance metrics, number and type/model/series of aircraft, sortie generation requirements, supply support, organizational alignment, communication effectiveness and many more,” said Hartigan (NAVAIR, 2011). 


\section{F. NAVAL AVIATION LEAN TOOLS \\ What tools are being used to implement lean training in Naval Aviation? \\ 1. NAPP Metrics}

Several NAPP metrics have been established as an integral part of the Naval Aviator Production Process management. NAPP metrics are designed to meet all the following criteria:

- $\quad$ Consistent with overall Navy/Marine Corp aviator production strategy

- $\quad$ Link the key parts of the Naval Aviator Production Process

- $\quad$ Reflect what i’s really happening in the Naval Aviation Training process

- $\quad$ Designed to facilitate consolidation and roll-up for Senior Leadership

- $\quad$ Predictive to the extent possible to provide forewarning of potential down range problems

"The metrics are set of linked data elements that roll up bottom to top of the NAPP hierarchy. Cockpit charts are generated in the NAPP Integrated Production Data Repository (NIPDR) using data prepared at the lowest level aviator training and consolidated upward through the training process for summarization and analysis” (Sizemore, 2010, p. 34). 


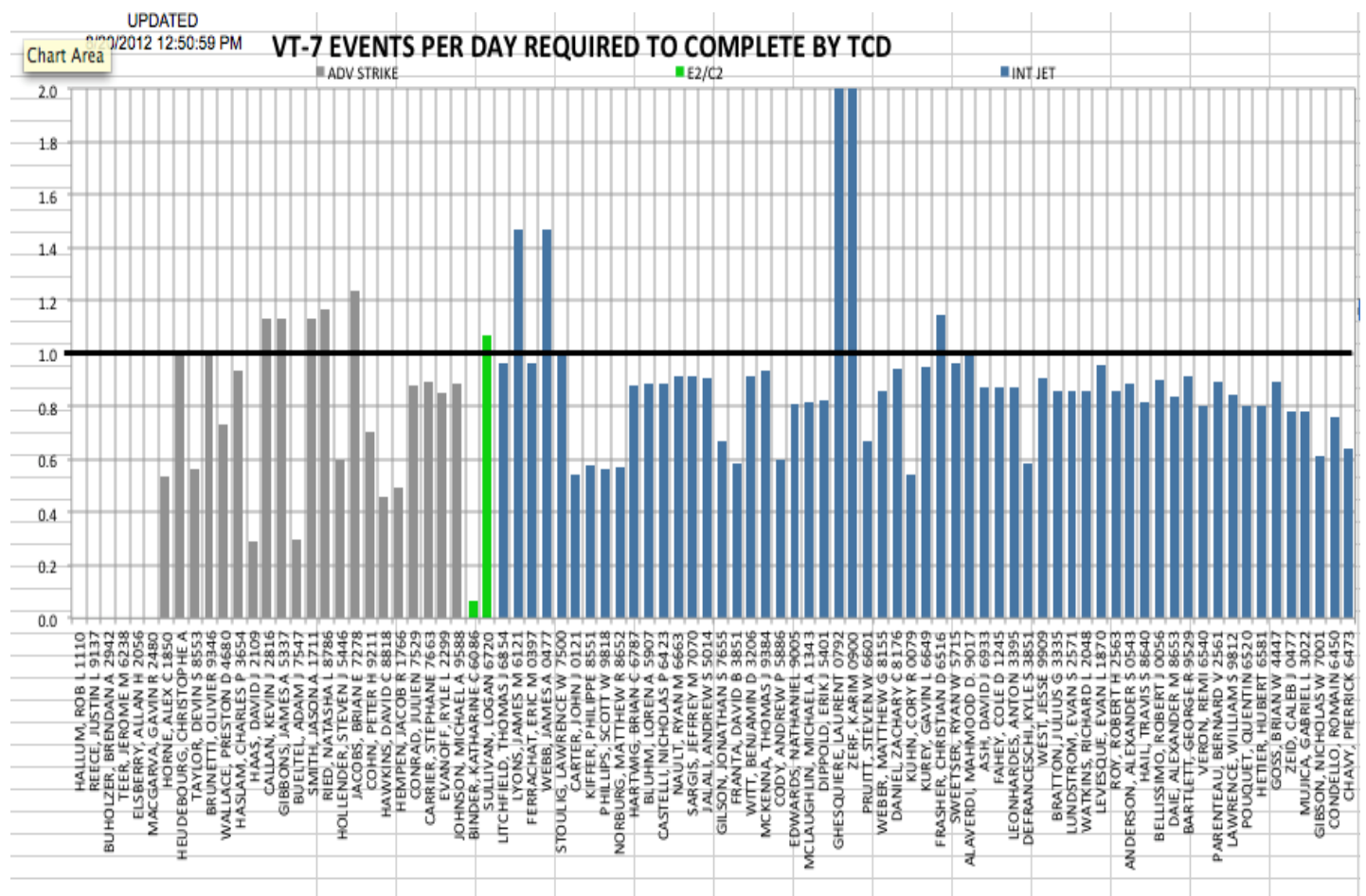

Figure 12. VT-7 Events Per Day Required

Figure 12 is similar to Figure 10, but shows all the USN and USMC students in VT-7. This metric shows the current state of every student in the squadron and required events per day that need to be scheduled in order for the student to exit at the required time-to-train. The black horizontal line indicates the optimum production requirement baseline of one event per day, per student. The Y axis is the number of events per day. Any student above the optimal line will need higher scheduling priority in order to meet the production demand signal. Squadron and wing leadership use this product on a daily basis to assist in making scheduling priority decisions. 


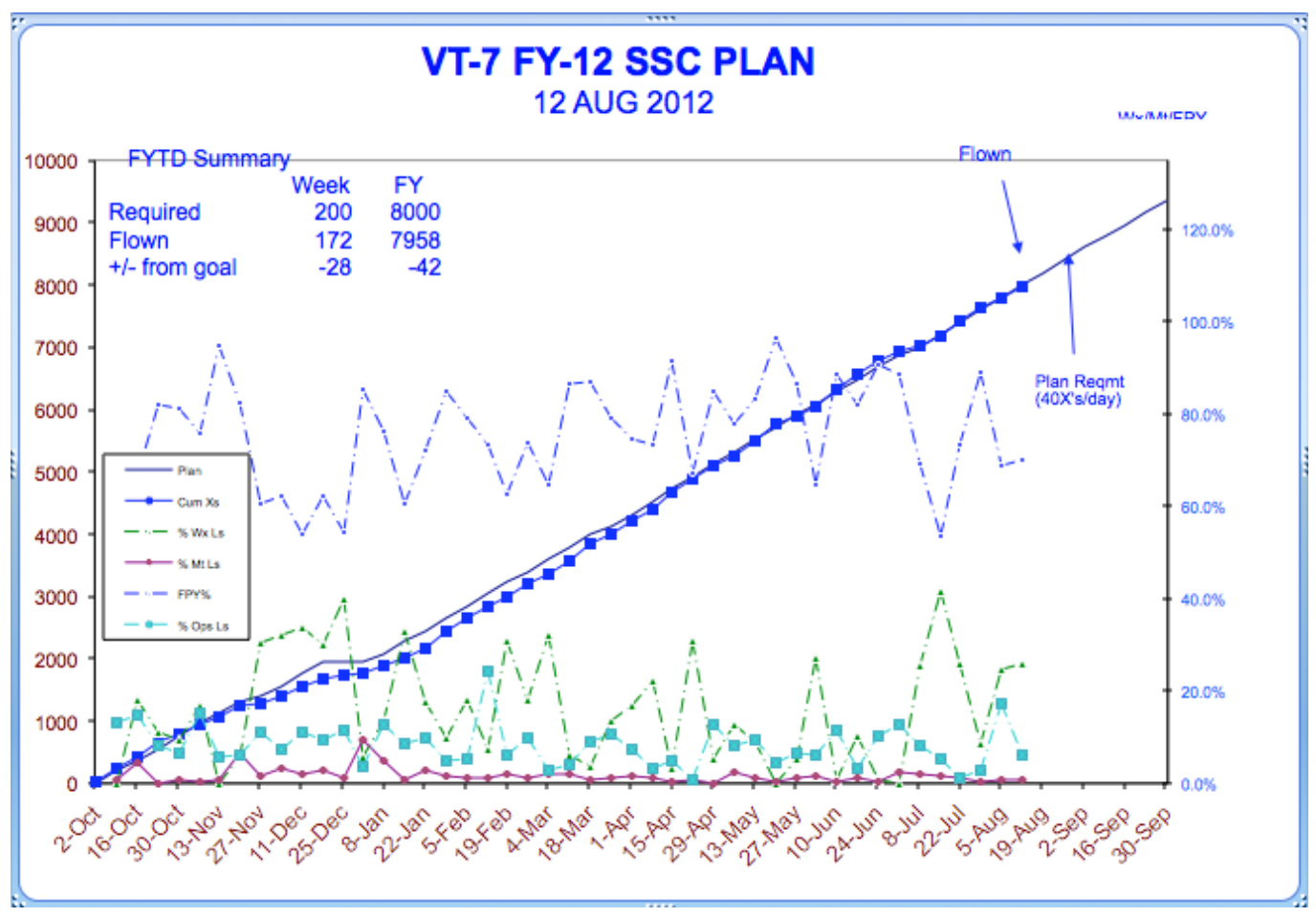

Figure 13. VT-7 Squadron Planned vs. Actual

Figure 13 is another example of a Squadron to Wing level NAPP metric. It gives local leadership a snapshot on how the Squadron is doing when compared to the planned production requirements. The solid blue line is often referred to as the "glide path." The squadron is above, on, or below the glide path when referring to whether or not it meets production requirements planned goals. The planned glide path is adjusted with IPP updated production requirements. Each $\mathrm{X}$ axis data point covers two week intervals starting at the beginning of FY12. The left $\mathrm{Y}$ axis is the cumulative number of events completed this FY. The right $\mathrm{Y}$ axis is the percentage of events completed vs. scheduled for each two week period. In Figure 13, production requirements dictate a need to complete 40 events (Xs) per day as the planned baseline. The lines located towards the bottom of the chart, show percentage of events lost due to maintenance, weather, and operational issues. Weather is typically the greatest contributor to lost/incomplete events. In the Figure 13 example, VT-7 is 42 events behind the planned 8000 for FY12. 


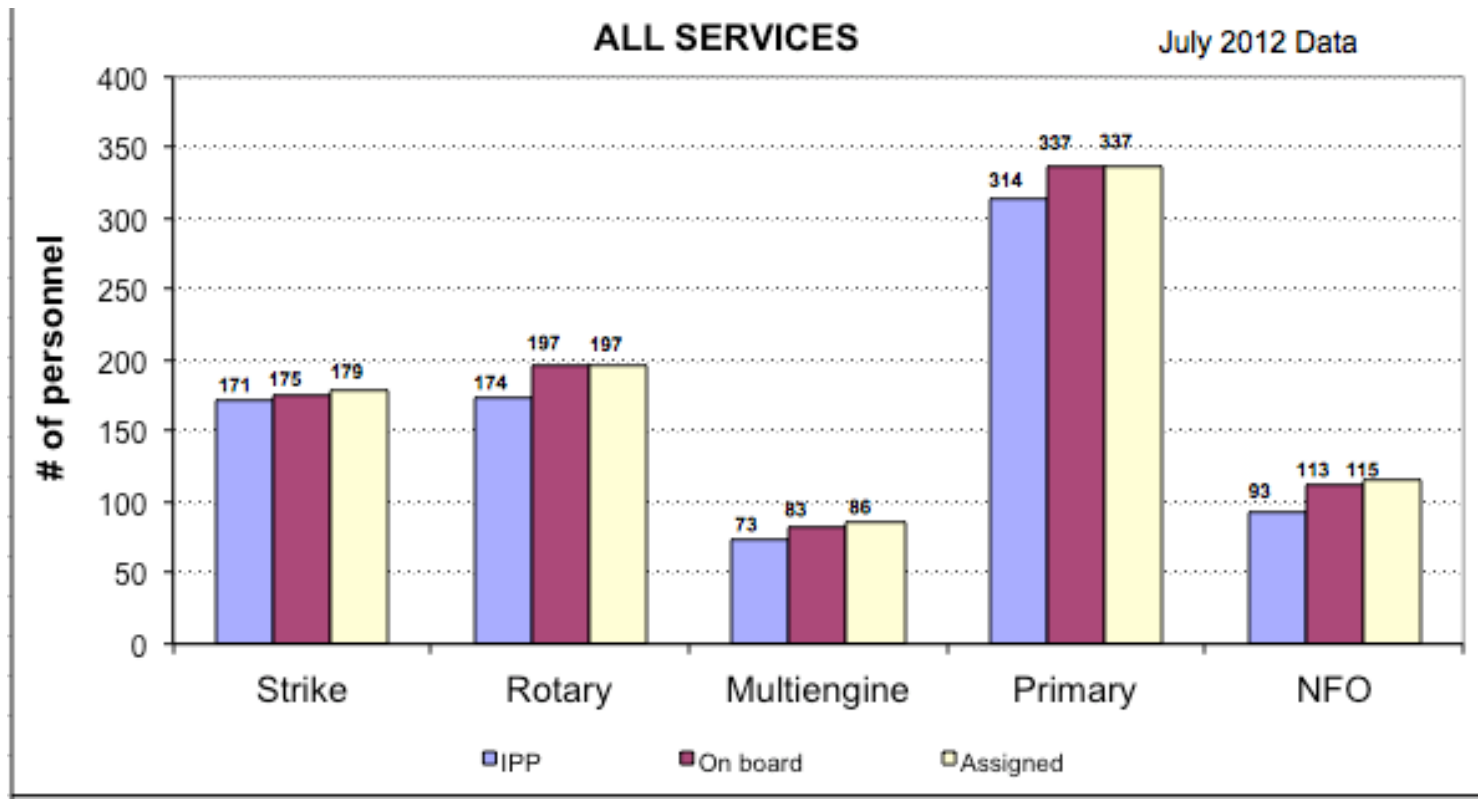

Figure 14. Instructor Pilot Manning

Figure 14 is another popular metric used in the NAPP. This chart provides leadership a general idea of how instructor manning compares to the required manning. Each pipeline is represented on the $\mathrm{X}$ axis of the chart. The $\mathrm{Y}$ axis is total number of Instructor pilots. The IPP requirement is annotated in blue. On board represents current instructor pilots filling a billet in that pipeline. The assigned block is the total number detailed or slated to that pipeline. Assigned personnel may have orders, but have not reported yet. In Figure 14, the current manning is above required for all pipelines.

\section{Training Integrated Management System (TIMS)}

The Training Integrated Management System (TIMS) was developed as an integral part of the T-6 Joint Primary Aircraft Training System’s (JPATS) ground based training system. TIMS combined and replaced five separate TRACOM training management systems and provided a single command-wide management system for both CNATRA and the Air Force Air Education Training Command. TIMS is the core of CNATRA's ground based training system and manages all aspects of undergraduate ground based flight training activities to include scheduling, creation of grade sheets and flight records, resource allocation, qualification and currency tracking, academics and 
computer aided instruction, long-range planning, and all training reports. TIMS also provides training connectivity between all CNATRA units using a linked network and has been chosen for the Joint Strike Fighter Program (Quinn, 2007). TIMS has not been implemented at the FRS level of Naval Aviation training.

\section{Multi-Service Pilot and NFO Training System (MPTS/MNTS)}

CNATRA and FRS training syllabi are in the process of converting from the old Navy Standard Score Grading convention we all used (aboves, averages, belows and unsats) to a new Multi-Service Pilot and NFO Training System (MPTS/MNTS). This new system enables a greater degree of course flow flexibility while providing more objective grading to ensure specific and required knowledge, skills and experiences are developed during each phase of aviation training. These skills and experiences are linked and tracked through a single network of task lists and learning objectives reaching back from the fleet all the way to a student aviator's first exposure to flight training. MPTS/MNTS enables each stage of training to be broken down into carefully designed training blocks to incrementally build and refine required skill sets. MPTS/MNTS incorporates Course Training Standards (CTS) that define specific parameters for each maneuver in order to reduce subjectivity in grading. The end product is targeted proficiency at each level of training to optimize efficiencies and ultimately ensure Student Naval Aviators and NFOs succeed in follow-on training venues (Quinn, 2007). MPTS is used to assure standardization in the Naval Avition training process to help reduce variability and increase product quality. Table 1 is an example of a Primary course training standard. A behavior statement or task must be demonstrated at the standard listed to assure with product quality control. 


\begin{tabular}{|c|c|}
\hline BEHAVIOR STATEMENT & STANDARDS \\
\hline \multicolumn{2}{|c|}{ 19. Approach Turn Stall (ATS) } \\
\hline $\begin{array}{l}\text { - Perform an approach } \\
\text { turn stall and recover } \\
\text { per the FTI. }\end{array}$ & $\begin{array}{l}\text { - Commences in the full-flap landing } \\
\text { configuration. } \\
\text { - Performs clearing turn. } \\
\text { - Enters stall at/above } 6500 \text { feet } \\
\text { AGL. } \\
\text { - Initiates recovery at stall entry. } \\
\text { - Loses less than } 150 \text { feet during } \\
\text { recovery. } \\
\text { - Recovers without secondary stall. }\end{array}$ \\
\hline \multicolumn{2}{|l|}{ 20. Spin } \\
\hline $\begin{array}{l}\text { - Spin and recover per } \\
\text { FTI. }\end{array}$ & $\begin{array}{l}\text { - Performs clearing turn. } \\
\text { - Enters spin at/above } 9000 \text { feet } \\
\text { AGL: } \\
\text { PCL idle. } \\
\text { - Pitch } 25-35 \text { degrees. } \\
\text { - AOB less than } 5^{\circ} \text {. } \\
\text { - Initiates proper recovery inputs } \\
\text { following a stabilized steady- } \\
\text { state spin. } \\
\text { - Recovers from ensuing unusual } \\
\text { attitude without exceeding } 4.5 \mathrm{G} \\
\text { or } 24 \text { AOA. }\end{array}$ \\
\hline \multicolumn{2}{|c|}{ 21. High Altitude Power Loss (HAPL) } \\
\hline $\begin{array}{l}\text { - Intercept the ELP at } \\
\text { or below high key } \\
\text { following a simulated } \\
\text { engine failure above } \\
2500 \text { feet AGL. }\end{array}$ & $\begin{array}{l}\text { - Maintains airspeed } 90-110 \text { KIAS. } \\
\text { - Selects suitable landing site. } \\
\text { - Establishes aircraft on final in } \\
\text { position to make a safe landing at } \\
\text { the selected site. }\end{array}$ \\
\hline \multicolumn{2}{|c|}{ 22. Low Altitude Power Loss (LAPL) } \\
\hline $\begin{array}{l}\text { - Intercept the ELP } \\
\text { following a simulated } \\
\text { engine failure between } \\
800 \text { and } 2500 \text { feet AGL. }\end{array}$ & $\begin{array}{l}\text { - Maintains airspeed } 90-110 \text { KIAS. } \\
\text { - Selects suitable landing site. } \\
\text { - Establishes aircraft on final in } \\
\text { position to make a safe landing at } \\
\text { the selected site. }\end{array}$ \\
\hline
\end{tabular}

\section{Table 1. $\quad$ Primary Course Training Standard (From: Crabbe, 2009)}

\section{Future Tools}

Only recently was the need to truly define value in Naval Aviation training initiated through a contract awarded in July 2012 to Lone Star Aerospace (LSA). The proposed contract is to provide predictive business and technical analysis, simulation and consulting services in order to address both short and long-term issues for the Naval Air Systems Command (NAVAIR), NAVAIR Headquarters, and the Naval Aviation Enterprise (NAE). The goals of the services include:

- Support of existing in production data collection and data collection systems.

- Analysis, modeling and simulation including data collection and validation, requirement derivation and analysis, quantitative and qualitative analysis. 
- $\quad$ Modeling personnel and processes, decision and other modeling, business case and benefit cost modeling, total ownership cost modeling, should cost could cost, analysis of alternative modeling, performance modeling.

- $\quad$ Scenario based simulations, "what if" simulations, gaming simulations, performance simulations, simulation delivery and reports, briefings and studies.

- $\quad$ Operation support including implementation and planning support, spiral model evolution, training and sustaining support of deployed models.

- $\quad$ Customer satisfaction measurement.

- $\quad$ Other analysis including enterprise environmental scans and assessments, industry/competitive analysis and assessments, red cell opportunity/ capability analysis, revision of existing data and implementation planning and support.

Lone Star Aerospace is the only known company to provide the TruNavigator tool for integrating a sophisticated version of Bayesian inference with Monte Carlo analysis in a single highly-scalable device, facilitating a Delphi-like process which allows groups to consider multiple "what-if" benefits and consequences in real time, and quantitatively ranking all potential outcome options in terms of the areas of greatest potential. In addition to this proprietary tool, Lone Star Aerospace has collected a significant amount of NAVAIR data that will continue to be utilized through spiral development combining collected data with data from LSA-proprietary databases containing DoD technical, cost and programmatic information. Lone Star Aerospace is also the only known company to provide operational sustainment support for existing, fielded simulations. It is estimated that it would take a minimum of 24-36 months, and approximately $\$ 2.9 \mathrm{M}$ for another vendor to develop a thorough understanding of all the complex systems being utilized within NAVAIR, as well as collecting data that has already been collected (DON, 2012, p. 1). 
THIS PAGE INTENTIONALLY LEFT BLANK 


\section{ANALYSIS}

\section{A. SPECIFY VALUE IN TRAINING}

\section{How do you define value in Naval Aviation training?}

"Lean thinking must start with a conscious attempt to precisely define value in terms of specific products with specific capabilities offered at specific prices through a dialogue with specific customers. The way to do this is to ignore existing assets and technologies and to rethink firms on a product-line basis with strong, dedicated product terms” (Rich, 2001). Although, value of training is loosely defined through command mission statements and curriculums, there is no conduit for feedback from the fleet customer on the value of the product or how well the product is doing. Typically little to no feedback is utilized between Commands to determine the quality of the previous phase of training. Curricula tend to focus on value addition based on the capability of their aircraft/simulators being utilized for that phase of training.

\section{B. TRAINING VALUE STREAM}

How do you identify and integrate management of the entire Naval Aviation training value stream?

Activities that can't be measured can't be properly managed. The activities necessary to create, order, and produce a specific product which can't be precisely identified, analyzed, and linked together cannot be challenged, improved (or eliminated altogether), and eventually, perfected. The great majority of management attention has historically gone to managing aggregates-processes, department, firms-overseeing many products at once. (Womack \& Jones, 1996, p. 37)

The value stream for Naval Aviation Training has changed dramatically since the inception of NAPP. Time-to-train and student pooling/batching has been greatly reduced. The NAPP process has also greatly improved the management of Naval Aviation Training. At any one time leadership can get a snapshot of how well units within the training continuum are meeting production goals. However, the department style processes still exist today with multiple training phases in several different regions 
of the country. NAPP has created a new transparency in the training continuum and means of precisely tracking production, but the separate training phases have little insight into the other phase's value added training steps.

\section{TRAINING FLOW}

\section{How do you design a production training systems that ensure training flows?}

The first step, once value is defined and the entire value stream is identified, is to focus on the actual object-the specific design, the specific order, and the product itselfand never let it out of sight from beginning to completion. The second step is to ignore the traditional boundaries of jobs, careers, functions and firms to form lean enterprises. The third step is to rethink specific work practices and tools to eliminate waste so the product can proceed continuously (Womack \& Jones, Lean Thinking, 1996). Naval Aviation Training is so complex that flow can be a very difficult to design or change. NAPP has helped with flow between phases of training, but flow impediments and waste are still apparent in several areas:

Overproduction-The overproduction of Naval Aviators is usually not an issue with NAPP. The original purpose of NAPP was to help fix gross underproduction issues. However, with the possibility of rapid defense budget cuts an overproduction event could occur. Overproduction would mean highly skilled and trained individuals would essentially have nothing to do while waiting for a fleet billet or their next phase of training to open. Overproduction is mainly an issue with a large rapid decrease in the production requirements. Recently, the Marine Corps pilot production requirements have been greatly reduced causing an immediate reduction in scheduling priority of Marine students in Advanced Jet training. By the time students get to advance level training they have been in the training pipeline for over a year. Due to the length of the value stream Pilot accession adjustments will not be felt downstream for up to a year. This situation can reduce the value added to the Marine students in two ways. The students have more days between events reducing learning and value added. They could also make it through in the normal time-to-train, but will sit for months waiting for an FRS spot or Fleet billet 
to open, creating a pooling situation. This overproduction situation is a good example of waste that starting to occur in the Naval Aviation training value stream.

Unnecessary stock-The Naval Aviation Enterprise still operates on a batch mentality even after the development of the NAPP. However, the NAPP program has produced less pooling of students as they transition to other phases of training. The NAPP approach to managing student inventory is to accumulate the excess students in pools in front of the training continuum and provide for a smooth uninterrupted flow once training begins (Sizemore, 2010). Instead of officially pooling students between phases students stagnate or are expedited during that phase. The flow is not consistent throughout the phase based on changing priority of the student scheduling.

Production quality defects-Course training standards help to keep production quality level high, but attrition still occurs. Attrition of a student (production quality defect) can happen at any time during training pipeline. The further down the pipeline the student attrite, the greater loss in value and ROI for the Naval Aviation Enterprise. The MPTS system allows better tracking of individuals that have issues within that phase of flight training, but does not necessary flag them for possible future problems in the next phase. Late FRS attrite can be a huge loss in investment for the Naval Aviation Enterprise.

Delays-Internal squadron delays exist as students flow from one block of training to the next. New students are given lower scheduling priority over students that are in later blocks of training. Lower priority means less flying and greater chance of reduced quality or performance. The scheduling process although should be simplified with TIMS is still manually accomplished day to day on a wall size dry erase board with magnetic pucks.

Unnecessary transport-Before a Naval Aviator enters the fleet he or she may move 4-5 times due to the varying locations of the different phases of flight training and final fleet squadrons. This is a huge waste in resources due to the high cost of PCS moves and delays between phases. 
Inappropriate processing - Continuous curriculum improvements identify relevant skill sets that are tracked throughout the syllabus. Human Performance analysis assists in identifying the correct training sequence and media. The benefit of this approach is the capability to shift training to the most appropriate and lowest cost asset. A primary theme of CNATRA21 is the increased use of high fidelity simulation across all training tracks to meet training goals with quality instruction, in the optimum learning environment, at the lowest cost (Quinn, 2007). High fidelity simulation has not been introduced in all phases of flight training and studies are on going to help determine possible future download of events into other lower cost platforms.

Unnecessary motion-There are some syllabus flights that may or may not add value to the learning and are redundant in content. The NAPP, TIMS and MPTS have allowed for more quantifiable process data, but the general design of the curricula have not changed much since the Cold War era. Recent contract awards are working quantifying each event, in every phases of training to determine the total value added. These studies will help in determine the effects and risk associated with changing the flow of training.

\section{TRAINING PULL} needs?

How do you introduce a pull training production system to support customer

The NAPP program manages the pull training requirements well, but due to the length of the value stream changes in production requirements can take several months to equalize and may cause on accordion effect in the value stream.

\section{E. TRAINING PERFECTION}

How do you continuously improve all business activities to achieve perfection in training?

Lean producers develop the mechanisms required to promote and capture innovations throughout the factory and to implement these quickly to improve the overall flow of material in the factory (to ensure a high quantity of improvement ideas). To benefit from these innovations the lean organization invests in widespread training, especially in the 
processes of asset management (to ensure the quality of improvement suggestions) and develops forums appropriate to integrate innovations proposed by suppliers and customers. (Rich, 2001, p. 5)

The NAPP has exposed top-level leadership and management to lean enterprise fundamentals, however, the instructors doing the day-to-day operations have little exposure to lean thinking. The typical squadron instructor has no idea what the production goals are for the organization, let alone for the entire value stream. At the squadron level there are several opportunities to take advantage of lean thinking and process improvements if personnel have the right training. Lean training would benefit operations personnel in reducing waste in the production of the daily flight schedule. Operations scheduling errors have the second highest effect on event cancellation only behind the weather. Standardization officers could benefit from Lean training to help redesign a curriculum flow that would allow for more multi-path value streams. More multi-flow paths would allow for increased flexibility in scheduling options during inclement weather days and help reduce bottlenecks. 
THIS PAGE INTENTIONALLY LEFT BLANK 


\section{CONCLUSIONS AND RECOMMENDATIONS}

\section{A. SUMMARY}

Naval Aviation has made some great strides in working towards more lean operations. The NAPP and other lean initiatives have reduced the Naval Aviator timeto-train by as much as $30 \%$. This reduction was mainly done using metrics to accurately track production and the inclusion of all stakeholder leadership in planning/execution. There have also been large gains in the implementation of Enterprise Transformation principles, like securing leadership commitment to drive and institutionalize enterprise behaviors, but more effort needs to be done in defining value at the lowest level and continued removal of waste.

\section{B. RECOMMENDATIONS}

\section{How do you define value in Naval Aviation training?}

"Lean thinking must start with a conscious attempt to precisely define value in terms of specific products with specific capabilities offered at specific prices through a dialogue with specific customers. The way to do this is to ignore existing assets and technologies and to rethink firms on a product-line basis with strong, dedicated product terms” (Rich, 2001, p. 1). Value in training has been typically defined by each individual phase of training and the next phase just accepted the product they got regardless of defect. Defining value continues to be a moving target as more advanced aircraft are being developed. Aircraft of today require less stick and rudder skills and more system management skills. Until value is precisely defined by the ultimate customer and clearly articulated throughout the enterprise the first step in Lean will never be fully realized.

How do you identify and integrate management of the entire Naval Aviation training value stream?

One of the goals of the Lone Star contract is to accurately map the value stream and model the effect of changes to the Naval Aviator training flow. Data collection that 
was included as part of the contract award was the convening of a Training Effectiveness Workshop. The workshop was a gathering of subject matter experts (SMEs) from all pipelines and phases of flight training to essentially analyze the entire training value stream. The participant SMEs included flight instructors, simulator instructors, NAWCTSD personnel, CNATRA leadership, Training Wing leadership, and Lone Star Aerospace employees. "Value" was officially defined for each pipeline as specific skill sets. These are skill sets required of a Naval Aviator at completion of FRS training. The Strike/Fighter pipeline skills included Pre and Post flight Mission Planning, Aircraft Handling, Air-to-Air Employment, Air-to-Ground Employment, Sensor Employment, Flight Admin, Carrier Qualification, and Survivability. The subject matter experts then proceeded to go through every block of training to determine effectiveness or "value added” by each block for each specific skill.

The workshop was a good first step in getting buy-in from multiple stakeholders, but it had some limitation in scope. Most SMEs were very well versed in their particular phase of training, but were not very familiar with other phases. They may have been through the other phases of training in the past, but it could have been over 10 years ago. During that period some major changes have occurred in most pipelines. To be more effective in providing meaningful contributions, the SMEs should have had recent experience in all phases of training. An exchange program with the SME allowing several weeks of immersion in each phase for their particular pipeline would have proven more beneficial for the Lean enterprise. This would provide a more informed experienced cross-functional team of experts that could have provided better inputs into the Lone Star model.

\section{How do you design a production training system that ensures flow?}

Many of the principles of Lean Flow-reduced batching, continuous flow, minimized waiting between steps-are about optimizing the whole process, not just individual steps. All too often one can see that because there is no overall process ownership or visions, that each person in the process optimizes their own activities without understanding the impact on the whole process flow. 
Optimizing the entire training process requires complete analysis and acceptance by all process owners. One example of a flow change that should be considered is the download of air-to-air employment training from the FRS to the advanced phases. This syllabus download or flow change could save money in the long run and help with FRS production shortfalls. Several issues with syllabus downloads need to be addressed before it can be accomplished. Advanced phase aircraft may lack the necessary attributes to accomplish the type of training required. Cultural barriers between phase instructors need to be minimized. Instructors would need the appropriate skill sets in all phases for the required download. This new look at the training value stream may require a whole re-design of Naval Aviation training systems in order to achieve a "best value." Lone Star's contract work should give Naval Aviation Enterprise leadership the advanced tools needed to make a true lean transformation in how Naval Aviators are trained.

At the squadron production level, several areas need improvements to flow and waste reduction processes. Scheduling flow is the greatest challenge at the squadron level. A squadron is allocated a finite number of aircraft per day from the Training Wing. It is the Scheduling Officer's responsibility to schedule up to 50+ flights a day, not including simulators. That individual must take into consideration NAPP metrics, instructor and student availability, instructor qualifications, crew rest requirements, airspace availability, and 80 different student flows. Due to the sheer work of writing a schedule a Scheduling Officer typically does not fly during the week they are scheduling, resulting in 10 lost events for that instructor. More research is recommended into squadron level scheduling to further analyze lean efficiencies that could be gained in the scheduling process. This research should investigate the possibility of contractor or government civilian position as a professional schedule writer. The research should also investigate the efficiencies of the Air Force "Flight" concept. The flight concept breaks a squadron up into dedicated product teams with dedicated instructors for specific students. Each flight is allocated its own aircraft to utilize for their events. The flight is able to manage its own scheduling and student flow more closely than the Navy scheduling process. 
To further remove waste and improve flow, training phases need to move closer or collocate with other phases. More research needs to be completed on the feasibility of collocating primary and intermediate/advance pipelines. This would greatly reduce the unnecessary movement of the product and reduce transportation costs.

\section{How do you introduce a pull training production system to support customer} need?

The NAPP pull process seems to be working as designed, but the length of the value streams need to be reduced to provide a more rapid response to fleet demand requirements. Further reduction in waste throughout the training process will increase the effectiveness of the NAPP pull response.

How do you continuously improve all business activities to achieve perfection in training?

The concept of perfection in lean production means that there are endless opportunities for improving the utilization of all types of assets. The systematic elimination of waste will reduce the costs of operating the extended enterprise and fulfills the customer's desire for maximum value at the lowest price. While perfection may never be achieved, its pursuit is a goal worth striving for because it helps maintain constant vigilance against wasteful practices. Perfection in the business of training Naval Aviators requires more training and exposure to the lean concepts at the grass roots level. Incentives need to be implemented to help spur new ideas in creating lean initiatives. Incentives could include reduced workload for instructors, professional recognition and even monetary rewards. Resistance to change is very apparent in all phases of flight training and smashing inertia will require strong leadership setting achievable, timely goals. Lean systems can only flourish if everyone along the value stream believes the new system can succeed. 


\section{LIST OF REFERENCES}

CNATRA. (2012). Aviator training. Retrieved from CNATRA:

https://www.cnatra.navy.mil/training_pilot.htm

CNATRA. (2012). Home. Retrieved from CNATRA:

https://www.cnatra.navy.mil/index.htm

CNATRA. (2005). The CNATRA training programimprovement program (CNATRAINST 1550.6E $\mathrm{CH}-1)$. CNATRA.

Commander Naval Air Forces. (2012). Enterprise airspeed history. Retrieved August 2012, 25, from Naval Avition Enterprise: http://www.cnaf.navy.mil

Crabbe, J. A. (2009). Primary multi-service pilot training system (CNATRAINST 1542.140D). Corpus Christi: CNATRA.

Crabbe, J. A. (2011). T-45 Combined flight training curriculum (CNATRAINST 1542.159). Corpus Christi: CNATRA.

Dershin, H. (2004). Lean and Six Sigma-The twain have met. European CEO. London: Tower Business Media.

DON. (2012). Justification and approval for use of other than full and open competition. China Lake: NACWD.

Levinson, W.A. (2002). Henry Ford's lean vision: Enduring principles from the first Ford motor plant. New York: Productivity Press.

Moore, D. L. (2007, March 27). Naval aviation enterprise AIRSpeed, transforming the end-to-end value stream. Patuxent River: NAVAIR.

N88. (2000). NAPPI background and talking points. Retrieved from Home: http://www.hq.navy.mil/airwarfare/navysite/navhome.htm

NAVAIR. (2011, April). PMA-273 program manager nominated for 2011 Aviation Week Laureate Award. Retrieved from NAVAIR News:

http://www.navair.navy.mil/index.cfm?fuseaction=home.NAVAIRNewsStory\&id $\underline{=4557}$

Nightingale, D. J., \& Srinivasn, J. (2011). Beyind the lean levolution. New York:

Amacom Management Association.

Quinn, D. P. (2007). CNATRA21 strategic vision. Corpus Christi: CNATRA.

Rich, N. (2001). An executive guide tolean thinking. Cardiff: Cardiff Business School. 
Sizemore, W. G. (2010). Naval aviator production process standard operating procedures (SOP). Corpus Christi: Department of the Navy.

Supple, J. (2012, April 01). CNATRA uses mathematical modeling to predict the future. Retrieved from AUSN:

http://www.ausn.org/NewsPublications/Magazine/MagazineArticles/tabid/2170/I D/15719/CNATRA-uses-mathematical-modeling-to-predict-the-future.aspx

VFA-106. (2012). Welcome. Retrieved from VFA-106 Official Website: http://www.public.navy.mil/airfor/vfa106/Pages/default.aspx

VT-3. (2012). Welcome. Retrieved from VT-3 Red Knights: http://www.cnatra.navy.mil/tw5/vt3/index.asp

VT-7. (2012). Welcome. Retrieved from Training Squadron Seven (VT-7): http://www.cnatra.navy.mil/tw1/vt7/index.asp

Womack, J. P., \& Jones, D. T. (1996). Lean thinking. New York: Free Press.

Womack, J. P., Jones, D. T., \& Ross, D. (1990). The machine that changed the world. New York: Free Press. 


\section{INITIAL DISTRIBUTION LIST}

1. Defense Technical Information Center

Ft. Belvoir, Virginia

2. Dudley Knox Library

Naval Postgraduate School

Monterey, California

3. CAPT David Lobdell

Training Wing One

Meridian, Mississippi

4. Dr. Keebom Kang

Naval Postgraduate School

Monterey, California 